\title{
Estudo e proposição de soluções sintéticas de solos para avaliação da corrosividade do aço X65
}

\section{Study and proposal of synthetic solutions of soils to evaluate the corrisivity on X65 steel}

\author{
Joseane Moreira Giarola ${ }^{1}$, Bernardo Augusto Farah Santos, ${ }^{1}$, \\ José Antônio Ponciano Gomes, ${ }^{2}$, Patrícia Benedini Martelli ${ }^{3}$, \\ Alysson Helton Santos Bueno
}

\author{
${ }^{1}$ Departamento de Engenharia Mecânica - Universidade Federal de São João Del Rei CP 36.307-352, São João del Rei, \\ MG \\ e-mail: josegiarola@gmail.com; bernardo.a.fs@hotmail.com; alyssonbueno@ufsj.edu.br \\ ${ }^{2}$ Departamento de Engenharia Metalúrgica e de Materiais - Universidade Federal do Rio de Janeiro, Centro de Tecnolo- \\ gia, bloco F, Ilha do Fundão - Rio de Janeiro, RJ, Brasil. \\ e-mail: ponciano@metalmat.ufrj.br \\ ${ }^{3}$ Departamento de Ciências Naturais - Universidade Federal de São João Del Rei, São João del Rei, MG \\ e-mail: martelli@ufsj.edu.br
}

\section{RESUMO}

As estruturas enterradas (tanques, bases de linhas de transmissão e dutos) estão expostas a diferentes tipos de solos e níveis de corrosividade. Neste caso, se torna necessário o estudo de corrosão do aço carbono nestes diferentes tipos de solos. Para estudos em laboratório, utiliza-se a solução NS4 para simular solos sintéticos. No entanto, devido aos diversos tipos de solos, é necessário o desenvolvimento de soluções sintéticas para simular estes solos com diferentes níveis de corrosividade. Assim, o objetivo deste trabalho foi desenvolver soluções sintéticas para uso em laboratório que abranjam uma variedade de tipos de solos com diferentes propriedades físico-químicas. Os ensaios eletroquímicos realizados foram curvas de polarização potenciodinâmicas, impedância eletroquímica e perda de massa. As soluções foram desenvolvidas alterando as concentrações da solução padrão NS4 nas seguintes condições: desaerada, na qual foi adicionado tiossulfato de sódio para simular o ambiente anaeróbico das bactérias redutoras de sulfato; em condições aeradas para simular solos contaminados com sulfeto de hidrogênio; adicionando cloreto de sódio para simular solos em região costeira e adição de cimento para simular solos anticorrosivos. Os resultados mostraram que o aço carbono apresenta maior taxa de corrosão quando exposto a soluções de cloreto de sódio e tiossulfato. A adição de 5\% $(\mathrm{m} / \mathrm{v})$ de cimento foi o suficiente para simular solos anticorrosivos, nos quais ocorreu o processo de passivação. Para garantir o processo passivo no metal nas soluções sintéticas com a presença de tiossulfato de sódio foi necessária adição $5 \%(\mathrm{~m} / \mathrm{v})$ de cimento. O processo de passivação estável não foi alcançado nas soluções sintéticas com cloreto de sódio ao se adicionar 5\%, 10\% e 15\% (m/v) de cimento.

Palavras-chave: Corrosividade dos solos, soluções sintéticas de solo, cimento, tiossulfato de sódio e cloreto de sódio.

\section{ABSTRACT}

The buried structures (tanks, bases of line transmissions, pipelines) are commonly exposed to different kind of soils and corrosivity levels. Due to this condition, it is necessary to study the corrosion on the carbon steel on these different environments. In laboratory, the NS4 solution is used to simulate synthetic soils. However, due to different kind of soils, it is necessary to develop synthetic solutions that evaluate these soils and their corrosivity. Therefore, the objective of this work was to develop synthetic solutions for laboratory use that include a large variety of kinds of soil with different physicochemical properties. The performed electrochemical tests were polarization curves, electrochemical impedance and mass loss. The solutions were obtained by altering the concentration of a standard solution of NS4 in these following conditions: in deaerated condition, in which was added sodium thiosulphate to simulate anaerobic environment of sulphate-reducing 
bacteria; in aerated conditions to simulate soil with the presence of $\mathrm{H}_{2} \mathrm{~S}$; adding sodium chlorate to simulate seashore areas and cement to simulate anticorrosive soils. The results demonstrated that carbon steel presents the lowest resistance to corrosion when exposed to sodium chlorate and thiosulphate solutions. Adding 5 wt. \% of cement was enough to simulate anticorrosive soils, in which the passivation process occurred. To ensure the passivation process actually takes place on the metal immersed in synthetic solution with sodium thiosulfate was necessary to add 5 wt. \% of cement. The stable passivation process was not reached in synthetic solutions with sodium chlorate when adding 5,10 and 15 wt. \% of cement.

Keywords: Soil corrosivity, synthetics soil solutions, cement, sodium thiosulphate and sodium chlorate

\section{INTRODUÇÃO}

A maior parte das pesquisas relativas a solos estão focadas na melhoria das propriedades mecânicas, que podem estar direta ou indiretamente relacionadas a resistência a corrosão. Contudo, os desenvolvimentos de métodos para evitar processos de corrosão em estruturas metálicas enterradas não são muito estudados [1].

O solo é conceituado como sendo uma camada de partículas minerais e de matéria orgânica, água, ar e seres vivos. Sua formação depende de vários fatores, como a degradação de rochas e plantas, clima, atividade biológica, topografia e tempo, com isso cada solo apresenta sua própria característica e propriedades que variam de acordo com a profundidade [2]. Devido a essa grande variedade de composição, a corrosividade do solo varia de forma bastante ampla [3].

Segundo Yan, et al. [4], a corrosão das estruturas metálicas está mais relacionada as propriedades físico-químicas do solo do que ao tipo de material usado. A corrosividade do solo é um importante fator associado ao processo de corrosão em estruturas enterradas, como dutos, tanques e linhas de transmissão que estão em abundancia em diferentes tipos de solos. Portanto, as análises de corrosividade do solo tornam-se necessárias pois podem evitar desastres ambientais e gerar economia de recursos financeiros [2].

A classificação da corrosividade do solo está associada às suas propriedades físico-químicas. Assim, a corrosividade do solo pode ser separada por agressividade relativa ou específica. A agressividade relativa está associada a interferências e problemas com a proteção catódica. A segunda depende das propriedades físico-químicas e bacteriológicas de solo, tais como a resistividade, $\mathrm{pH}$, acidez total, umidade, potencial redox, cloreto, sulfeto e bactérias redutoras de sulfato [5]. De acordo com a literatura, os solos com alta acidez, elevada resistividade e grande concentração de sais dissolvido são os mais agressivos [4].

Os íons cloretos $\left(\mathrm{Cl}^{-}\right)$elevam a condutividade do solo influenciando nas reações de dissolução anódica dos metais tornando-o vulnerável à corrosão. Estes íons geram uma diminuição no $\mathrm{pH}$ do solo ao produzirem ácido clorídrico. O aumento da concentração de íons cloretos tendem a diminuir a resistividade do solo, com isso eles se tornam prejudiciais às estruturas enterradas [7-9].

Os íons sulfatos $\left(\mathrm{SO}_{4}{ }^{2-}\right)$ no solo são associados a presença de matéria orgânica. No solo esses íons formam $\mathrm{FeSO}_{4}$ solúvel, o que o torna muito agressivo. Estes íons são considerados mais danosos que os íons cloretos, uma vez que os sulfatos podem ser convertidos em sulfetos, que são altamente corrosivos por serem consumidos por bactérias redutoras de sulfato. O processo de conversão do sulfato dificulta o hidrogênio atômico a formar hidrogênio molecular; o hidrogênio atômico pode acabar penetrando no metal por possuir tamanho reduzido, o que causa prejuízos em suas propriedades mecânicas [7-9].

Os íons sulfetos ( $\left.\mathrm{S}^{2-}\right)$ são resultantes do processo metabólico da redução do sulfato pelas bactérias redutoras de sulfatos (BRS) presentes no meio. A presença destes íons em concentrações maiores que 5 ppm indica que o solo é muito corrosivo, e mesmo pequenas quantidades são indesejadas, uma vez que indica a presença de BRS que acelera o processo de corrosão do metal [8, 9]. As bactérias redutoras de sulfato (BRS), encontram-se largamente distribuídas nos ambientes terrestres e aquáticos anaeróbicos. A presença de BRS com alta atividade metabólica é facilmente reconhecida pelo escurecimento da água e sedimentos do solo devido à precipitação de FeS, e o odor característico de sulfeto de hidrogênio $\left(\mathrm{H}_{2} \mathrm{~S}\right)$ [10].

A solução NS4 é amplamente utilizada para simular solos sintéticos. No entanto, Parkins [11] desenvolveu esta solução com base nas características físico-químicas de um determinado solo. Considerando esse fator, esta solução sintética não pode ser usada para simular todos os tipos de solo, devido à elevada complexidade das propriedades físico-químicas que os mesmos podem apresentar.

Os materiais utilizados para promover a estabilização e modificação do solo são chamados de materiais calcários. Eles modificam algumas propriedades do solo, como o aumento de capacidade de carga, resistência mecânica, permeabilidade e outros. É importante considerar que estas propriedades podem variar em função da temperatura, composição, umidade relativa e pH [1,6].

Assim, o objetivo deste trabalho foi desenvolver soluções sintéticas para uso em laboratório que 
abranjam uma variedade de tipos de solos com diferentes propriedades físico-químicas, como solos que apresentam bactérias redutoras de sulfato, solos anticorrosivos e solos de região costeira. A adição de tiossulfato de sódio em condições aeradas tem o intuído de simular solos contaminados com $\mathrm{H}_{2} \mathrm{~S}$, e em condições desaeradas simular ambientes anaeróbicos das bactérias redutoras de sulfato (BRS). O cimento foi adicionado para simular solos anticorrosivo, fazendo com que o aumento do pH promova a passivação do metal. Além disso, o cloreto de sódio foi adicionado para simular um solo em região costeira. Com base nessas propriedades, foi possível desenvolver soluções sintéticas para uso em laboratório, simulando solos contaminados e com diferentes propriedades físico-químicas.

\section{MATERIAIS E MÉTODOS}

As soluções sintéticas (Tabela 1) foram testadas em triplicada no aço carbono API X65.

Tabela 1: Composição química das soluções sintéticas de solo.

\begin{tabular}{|c|c|c|c|c|c|c|c|c|}
\hline \multirow[b]{2}{*}{ SOLUÇÃo } & \multirow[b]{2}{*}{ pH } & \multicolumn{7}{|c|}{ CONTEÚDO } \\
\hline & & $\begin{array}{l}\mathrm{KCl} \\
(\mathrm{g} / \mathrm{L})\end{array}$ & $\begin{array}{l}\mathrm{CaCl}_{2} \\
(\mathrm{~g} / \mathrm{L})\end{array}$ & $\begin{array}{c}\mathrm{NaHCO}_{3} \\
(\mathrm{~g} / \mathrm{L})\end{array}$ & $\begin{array}{c}\mathrm{MgSO}_{4} \cdot 7 \mathrm{H}_{2} \mathrm{O} \\
(\mathrm{g} / \mathrm{L})\end{array}$ & $\begin{array}{c}\mathrm{NaS}_{2} \mathrm{O}_{3} \cdot 5 \mathrm{H}_{2} \mathrm{O} \\
(\mathrm{g} / \mathrm{L})\end{array}$ & $\begin{array}{l}\mathrm{NaCl} \\
(\%)\end{array}$ & $\begin{array}{l}\text { Cimento } \\
\%(\mathrm{~m} / \mathrm{v})\end{array}$ \\
\hline 1 & 8,1 & 0,1220 & 0,0930 & 0,4830 & 0,1310 & 0 & 0 & 0 \\
\hline 2 & 8,1 & 0,1342 & 0,1023 & 0,4830 & 0,1310 & 0 & 0 & 0 \\
\hline 3 & 8,1 & 0,1220 & 0,0930 & 0,5310 & 0,1441 & 0 & 0 & 0 \\
\hline 4 & 8,2 & 0,1342 & 0,1023 & 0,5310 & 0,1441 & 0 & 0 & 0 \\
\hline 5 & 8,2 & 0,1220 & 0,0930 & 0,4830 & 0,1310 & 2,4810 & 0 & 0 \\
\hline $5^{*}$ & 8,2 & 0,1220 & 0,0930 & 0,4830 & 0,1310 & 2,4810 & 0 & 0 \\
\hline 6 & 8,1 & 0,1342 & 0,1023 & 0,4830 & 0,1310 & 2,4810 & 0 & 0 \\
\hline 7 & 8,2 & 0,1220 & 0,0930 & 0,5313 & 0,1441 & 2,4810 & 0 & 0 \\
\hline 8 & 8,2 & 0,1342 & 0,1023 & 0,5313 & 0,1441 & 2,7291 & 0 & 0 \\
\hline 9 & 12,8 & 0,1220 & 0,0930 & 0,4830 & 0,1310 & 0 & 0 & 5 \\
\hline 10 & 13,1 & 0,1220 & 0,0930 & 0,4830 & 0,1310 & 0 & 0 & 10 \\
\hline 11 & 13,2 & 0,1220 & 0,0930 & 0,4830 & 0,1310 & 0 & 0 & 15 \\
\hline 12 & 12,8 & 0,1220 & 0,0930 & 0,4830 & 0,1310 & 2,4810 & 0 & 5 \\
\hline $12^{*}$ & 12,8 & 0,1220 & 0,0930 & 0,4830 & 0,1310 & 2,4810 & 0 & 5 \\
\hline 13 & 13,1 & 0,1220 & 0,0930 & 0,4830 & 0,1310 & 2,4810 & 0 & 10 \\
\hline 14 & 13,2 & 0,1220 & 0,0930 & 0,4830 & 0,1310 & 2,4810 & 0 & 15 \\
\hline 15 & 8,1 & 0,1220 & 0,0930 & 0,4830 & 0,1310 & 0 & 3,5 & 0 \\
\hline 16 & 12,3 & 0,1220 & 0,0930 & 0,4830 & 0,1310 & 0 & 3,5 & 5 \\
\hline 17 & 12,4 & 0,1220 & 0,0930 & 0,4830 & 0,1310 & 0 & 3,5 & 10 \\
\hline 18 & 12,5 & 0,1220 & 0,0930 & 0,4830 & 0,1310 & 0 & 3,5 & 15 \\
\hline
\end{tabular}

A solução 1 corresponde a solução NS4, as 2 a 4 foram testadas com o intuído de simular algumas das possíveis variações na composição química da solução NS4. Para o caso das soluções com a adição do reagente Tiossulfato de sódio (soluções $5,6,7,8$ ), foram realizados ensaios em condições naturalmente aerada para simular solos contaminados com $\mathrm{H}_{2} \mathrm{~S}$. Bem como, em condições desaeradas (solução $5^{*}$ ) com o gás $\mathrm{N}_{2}$ puro para simular o ambiente anaeróbico das BRS.

O cimento foi adicionado às soluções 9, 10 e 11 para elevar o valor do pH até o meio ficar alcalino e simular um solo anticorrosivo. Nesse caso, foram avaliadas as relações quando se adicionou 5\%, 10\% e 15\% $(\mathrm{m} / \mathrm{v})$ de cimento na solução sintética NS4.

Após os ensaios com adição de cimento e tiossulfato de sódio separadamente na solução NS4, foram realizados estudos com a presença de ambos os reagentes. Neste caso, as soluções 12, 13 e 14, em condições naturalmente aeradas, pretenderam-se simular uma solução sintética de solo anticorrosivo contaminado com $\mathrm{H}_{2} \mathrm{~S}$. Enquanto que a solução $12 *$, desaerada com o gás $\mathrm{N}_{2}$, teve o intuito de simular uma solução de solo sintético anticorrosivo com a presença de BRS. A solução 15 aspira estudar solos de regiões costeiras, ou seja, próximas ao mar, que apresentam elevada quantidade de íons cloreto. Para finalizar as soluções 16, 17 e 
18 representam soluções de solos sintéticos anticorrosivos em regiões costeiras, ou seja, com íons cloreto e cimento.

Os ensaios eletroquímicos foram realizados com o auxílio de um AUTOLAB tipo Multi Autolab Cabinet potentiostat utilizando uma célula convencional de três eletrodos, na qual a mostra de aço carbono X65 foi o eletrodo de trabalho, a platina foi usada como contra eletrodo e o eletrodo de calomelano saturado (ECS) como eletrodo de referência.

As curvas de polarização anódicas e catódicas foram obtidas com uma taxa de varredura de 60 $\mathrm{mV} / \mathrm{min}$. Na impedância eletroquímica a amplitude utilizada foi de $5 \mathrm{mV}$ (ECS), com a frequência de $30 \mathrm{kHz}$ a $0,01 \mathrm{~Hz}$, com uma amplitude de $5 \mathrm{mV}$.

A perda de massa foi monitorada semanalmente. Após cada semana de imersão, os corpos de prova foram lavados, secados e pesados. E posteriormente os corpos de prova foram novamente imersos em soluções.

\section{RESULTADOS E DISCUSSÃO}

Segundo a literatura [12], o pH dos solos geralmente encontra-se numa faixa de 5 a 8,5. Neste caso, de acordo com Bueno e outros autores a solução NS4 tem um pH inicial em torno de 8,1, com o borbulhamento da mistura de gás $\mathrm{N}_{2}$ e $5 \% \mathrm{CO}_{2}$, o pH da solução cai para 6,5 a 7,0, objetivando simular um solo com pH próximo do neutro [13-15]. Como o autor já apresenta as curvas de polarização em solução NS4 desaerada com a mistura de gás $\mathrm{N}_{2}$ e $5 \% \mathrm{CO}_{2}$ não será necessário refazer estes ensaios neste trabalho.

A Figura 1 apresenta as curvas de polarização, catódica e anódica, obtidas com o aço API X65 nas soluções apresentadas na Tabela 1.
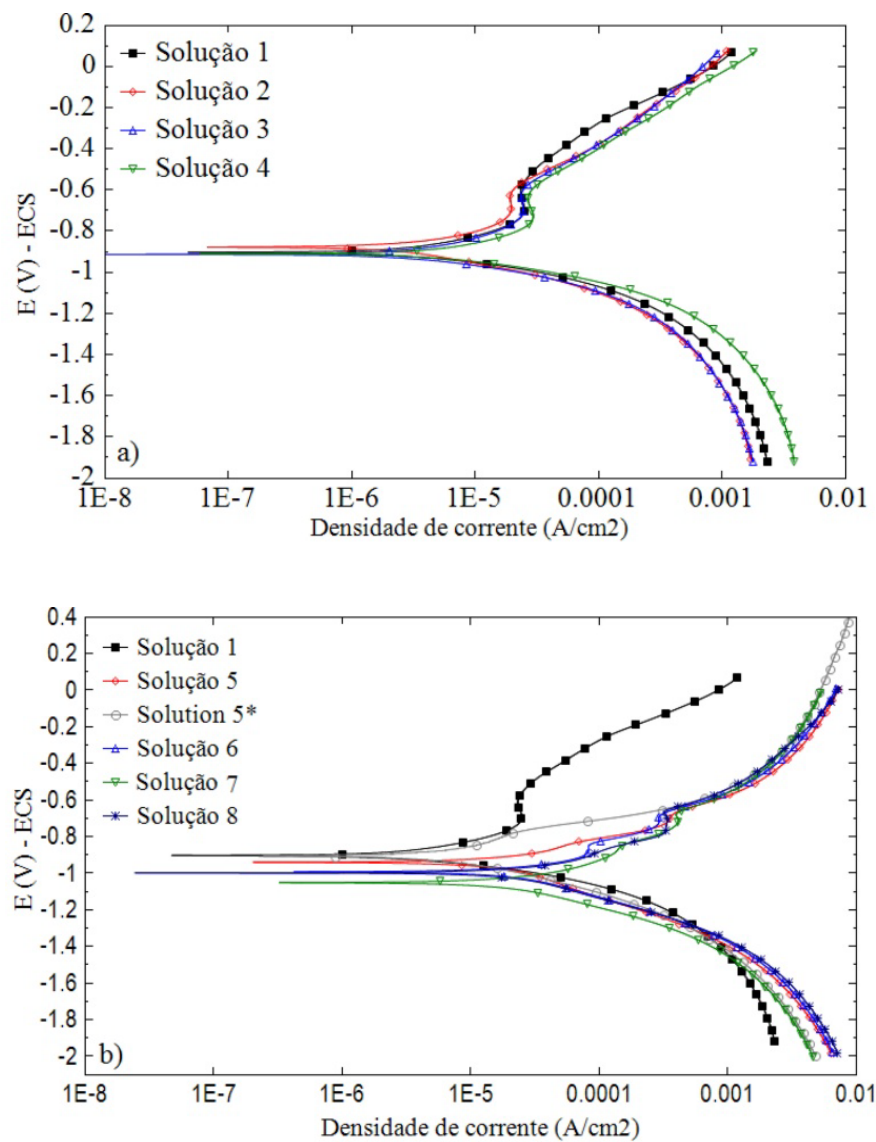

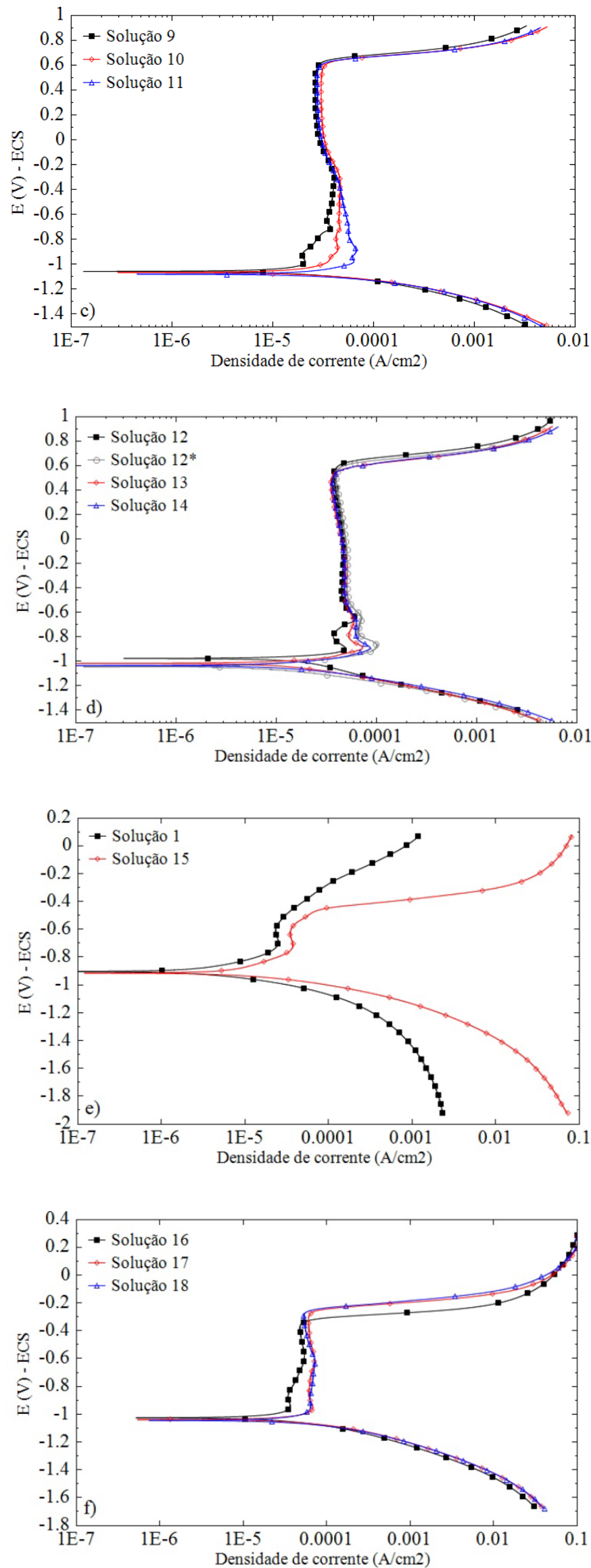

Figura 1: Curvas de polarização anódica e catódica, obtidas com o aço API X65 nas soluções de teste. 
As densidades de corrente catódicas observadas nas curvas de polarização para todas as dezoito soluções podem ser atribuídas à reação de redução de oxigênio e hidrogênio na superfície do eletrodo de trabalho.

A Figura 1(a) demonstra que as soluções 1 a 4 apresentaram dissolução ativa do metal sem ocorrer o processo de passivação numa faixa de $400 \mathrm{mV}$. Neste caso, a variação na composição dos reagentes da solução NS4 (solução 1) não causou mudanças significativas no comportamento das curvas e nos pHs.

Estes resultados estão de acordo com Bueno [13,15], Niu e Cheng [17], Ha et al.[18] em cujos estudos, foi observa dissolução ativa do aço em soluções de solo com pH no intervalo de 7 a 8,5. Este efeito é confirmado termodinamicamente pelo diagrama de Pourbaix [16], no qual o potencial a circuito aberto se situou dentro do domínio de corrosão. Contudo Gadala e Alfantasi [14], observaram um processo de passivação em pH próximos de neutro, isso devido a adição de bicarbonato. Porém em potenciais altos, outros processos de transporte de massa, como a dissociação da água, ocorrem na superfície do material. Assim sendo, as densidades de correntes observadas nestes potenciais podem não estar apenas associadas ao processo de corrosão. Desta forma, o processo de passivação descrito pelo autor necessita ser melhor avaliado.

A Tabela 2 indica que a segunda e quarta solução são mais agressivas do que a solução NS4 padrão (solução 1). Isso ocorreu porque elas apresentaram maior densidade de corrente em um potencial anódico aplicado a $50 \mathrm{mV}$ e a $100 \mathrm{mV}$ acima do potencial de corrosão, obtido pela Figura 1(a). Esta metodologia proporciona uma via para avaliar, em mesmas condições, diferentes curvas potenciodinâmicas, na qual o metal apresentou dissolução ativa. Nesse caso, é possível inferir que provavelmente o aumento na densidade de corrente nas reações anódicas ocorreram devido ao aumento da concentração de cloreto nas soluções 2 e 4. Alguns autores, relatam que os íons cloreto aumentam a condutividade do solo, ocasionando uma diminuição na resistividade o que favorece o processo corrosivo na superfície do metal [2, 5, 19].

Tabela 2: Valores de densidade de corrente obtidas para soluções sintéticas.

\begin{tabular}{cccc}
\hline SOLUÇÃo & $\begin{array}{c}\text { POTENCIAL DE CIRCUI- } \\
\text { TO ABERTO }(\mathbf{m V})\end{array}$ & $\begin{array}{c}\text { DENSIDADE DE CORRENTE } \\
\text { ANÓDICA A 50 MV ACIMA DO } \\
\text { POTENCIAL DE CIRCUITO } \\
\text { ABERTO }\left(\boldsymbol{\mu} / \mathbf{c m}^{2}\right)\end{array}$ & $\begin{array}{c}\text { DENSIDADE DE CORRENTE } \\
\text { ANÓDICA A 100 MV ACIMA DO } \\
\text { POTENCIAL DE CIRCUITO } \\
\text { ABERTO }\left(\boldsymbol{\mu} \text { A/cm } \mathbf{c m}^{2}\right)\end{array}$ \\
\hline 1 & $-719,00$ & 5,87 & 13,30 \\
2 & $-710,00$ & 6,33 & 13,44 \\
3 & $-721,00$ & 6,13 & 13,02 \\
4 & $-718,00$ & 9,58 & 19,83 \\
5 & $-781,00$ & 31,30 & 59,29 \\
$5 *$ & $-796,00$ & 9,14 & 16,75 \\
6 & $-777,00$ & 45,59 & 79,89 \\
7 & $-803,00$ & 39,36 & 80,23 \\
8 & $-782,00$ & 46,53 & 88,50 \\
15 & $-720,00$ & 11,15 & 20,60 \\
\hline
\end{tabular}

Analisando os resultados com base no diagrama de equilíbrio eletroquímico de Pourbaix [16] para o sistema $\mathrm{Fe} / \mathrm{H}_{2} \mathrm{O}$ a $25^{\circ} \mathrm{C}$, as soluções 1 , 2, 3 e 4 apresentaram potencial de corrosão, em condições naturalmente aeradas, que se situaram dentro do domínio de corrosão com solubilidade dos íons $\mathrm{Fe}^{2+}$ na concentração de $10^{-6}$ íon g $\mathrm{L}^{-1}$, e acima da linha de equilíbrio $\mathrm{H} / \mathrm{H}^{+}$(Tabela 3 ). Neste caso, a reação $\mathrm{Fe} / \mathrm{Fe}^{2+}$ de dissolução anódica ocorre termodinamicamente espontânea na superfície do aço sem ocorrer processo de passivação.

A redução de hidrogênio não ocorreu na superfície do metal, isso devido ao fato dos testes terem sido realizados em condições naturalmente aeradas. Desta forma, o potencial de corrosão se situou acima da linha de equilíbrio $\mathrm{H} / \mathrm{H}^{+}$segundo o diagrama de Pourbaix [16]. Porém, como verificado por Bueno [13,15], caso os ensaios de polarização sejam realizados em condições desaeradas, o aço imerso nas soluções irá apresentar um potencial de corrosão inferior à linha de equilíbrio $\mathrm{H} / \mathrm{H}^{+}$, isto provavelmente ocorreu devido o processo de desaeramento da solução com gás $\mathrm{N}_{2}$.

A diferença entre o potencial de corrosão e a linha de equilíbrio $\mathrm{Fe} / \mathrm{Fe}^{2+}$, indicados na Tabela 3 são as mínimas sobre tensões para alcançar a área necessária da imunidade, e a diferença entre o potencial de corrosão e a linha de equilíbrio $\mathrm{H} / \mathrm{H}^{+}$são as mínimas sobre tensões para que a reação de redução de hidrogênio se torne termodinamicamente espontânea na superfície do metal, de acordo com o diagrama de Pourbaix [16]. 
Tabela 3: Dados obtidos da curva de polarização para soluções sintéticas de solos.

\begin{tabular}{|c|c|c|c|c|c|c|}
\hline \multirow[b]{2}{*}{ SOLUÇÃo } & \multirow[b]{2}{*}{ pH } & \multicolumn{3}{|c|}{ POTENCIAL (mV, ECS) } & \multicolumn{2}{|c|}{$E(\mathrm{mV})$} \\
\hline & & CORROSÃO & $\begin{array}{c}\text { EQUIL. } \\
\mathrm{H} / \mathrm{H}+\end{array}$ & EQUIL. FE/FE2+ & $\begin{array}{c}\Delta \mathrm{E}_{\mathrm{H}} \\
\mathrm{E}_{\mathrm{CORR}}-\mathrm{E}_{\mathrm{H} / \mathrm{H}}\end{array}$ & $\begin{array}{c}\Delta E_{\mathrm{Fe}} \\
E_{\text {CORR }}-E_{\text {FelFe2+ }}\end{array}$ \\
\hline 1 & 8,10 & $-719,00$ & $-744,00$ & $-892,00$ & 25,00 & 173,00 \\
\hline 2 & 8,10 & $-710,00$ & $-719,00$ & $-892,00$ & 9,00 & 182,00 \\
\hline 3 & 8,10 & $-721,00$ & $-744,00$ & $-892,00$ & 23,00 & 171,00 \\
\hline 4 & 8,20 & $-718,00$ & $-731,00$ & $-892,00$ & 13,00 & 174,00 \\
\hline 5 & 8,20 & $-781,00$ & $-726,00$ & $-892,00$ & $-55,00$ & 111,00 \\
\hline $5^{*}$ & 8,20 & $-796,00$ & $-726,00$ & $-892,00$ & $-70,00$ & 96,00 \\
\hline 6 & 8,10 & $-777,00$ & $-732,00$ & $-892,00$ & $-45,00$ & 115,00 \\
\hline 7 & 8,20 & $-803,00$ & $-732,00$ & $-892,00$ & $-71,00$ & 89,00 \\
\hline 8 & 8,20 & $-782,00$ & $-732,00$ & $-892,00$ & $-50,00$ & 110,00 \\
\hline 9 & 13,50 & $-269,00$ & $-1012,25$ & $-1097,25$ & 743,25 & 828,25 \\
\hline 10 & 13,08 & $-280,00$ & $-1014,03$ & $-1099,03$ & 734,03 & 819,03 \\
\hline 11 & 13,12 & $-296,00$ & $-1016,32$ & $-1101,39$ & 720,39 & 805,39 \\
\hline 12 & 12,92 & $-203,00$ & $-1004,57$ & $-1089,57$ & 801,57 & 886,57 \\
\hline $12^{*}$ & 12,92 & $-357,00$ & $-1004,57$ & $-1089,57$ & 647,57 & 732,57 \\
\hline 13 & 13,16 & $-277,00$ & $-1018,76$ & $-1103,76$ & 741,76 & 826,76 \\
\hline 14 & 13,20 & $-255,00$ & $-1021,12$ & $-1106,12$ & 766,12 & 852,12 \\
\hline 15 & 8,10 & $-720,00$ & $-719,00$ & $-892,00$ & $-1,00$ & 172,00 \\
\hline 16 & 12,30 & $-457,00$ & $-967,93$ & $-1052,93$ & 510,93 & 595,93 \\
\hline 17 & 12,40 & $-461,00$ & $-973,84$ & $-1058,84$ & 512,84 & 597,84 \\
\hline 18 & 12,50 & $-478,00$ & $-979,75$ & $-1064,75$ & 501,75 & 586,75 \\
\hline
\end{tabular}

Pela Figura 1(b) observou-se uma variação significativa da densidade de corrente quando o tiossulfato de sódio foi adicionado na solução NS4 padrão (soluções 5, 6, 7 e 8), naturalmente aeradas. A solução 1, composta pela solução NS4 padrão, é menos agressiva do que as soluções 5, 6, 7 e 8 . Isto pode ser comprovado pela análise da Tabela 2, onde as densidades de corrente anódicas são bem maiores em relação a solução NS4 padrão.

Assim sendo, as soluções compostas por tiossulfato de sódio, em condições aeradas (soluções 5, 6, 7 e 8) mostraram densidade de corrente aproximadamente cinco vezes maior que solução 1. As soluções 6 e 8 apresentaram densidade de corrente aproximadamente sete vezes maior que a solução padrão NS4, medido a $50 \mathrm{mV}$ e $100 \mathrm{mV}$ acima do potencial de circuito aberto. Estas soluções contêm 10\% a mais em massa de $\mathrm{CaCl}_{2}$ e $\mathrm{KCl}$ que as demais soluções.

A densidade de corrente da solução 8 não apresenta um aumento significativo em relação as soluções 6 e 7, com isso podemos concluir que o acréscimo na concentração de tiossulfato de sódio não é necessário, uma vez que a concentração de 2,4810 g/L foi suficiente para simular a presença de $\mathrm{H}_{2} \mathrm{~S}$ gerada pelas bactérias redutoras de sulfato.

A Solução $5^{*}$ foi desaerada com gás $\mathrm{N}_{2}$ para simular a presença de bactérias redutoras de sulfato. Pela análise da Tabela 2 conclui-se que essa solução é menos agressiva do que a solução NS4 com acréscimo de tiossulfato de sódio naturalmente aerada (solução 5). Isso devido a ela possuir menor densidade de corrente em um potencial anódico aplicado a $50 \mathrm{mV}$ e a $100 \mathrm{mV}$ acima do potencial de corrosão ( $\mathrm{E}_{\text {corr }}$ ), essa menor agressividade ocorreu pela ausência de oxigênio na solução. Além disso, inicialmente, o potencial de corrosão praticamente não se alterou com a adição de tiossulfato de sódio em relação à solução padrão NS4. Somente ocorreu uma pequena queda no potencial de corrosão na solução $5^{*}$, após o seu desaeramento, que apresentou um potencial mais negativo que a solução 1 e 5.

Analisando a Tabela 3 e a Figura 1(b) o aço mostrou dissolução ativa em todas as soluções, por estarem acima da linha de equilíbrio $\mathrm{Fe} / \mathrm{Fe}^{2+}$, sem apresentarem tendência de passivação, ou seja, o potencial final de corrosão ficou situado dentro do domínio corrosão com solubilidade dos íons $\mathrm{Fe}^{2+}$ na concentração de 
$10^{-6}$ íon g L ${ }^{-1}$, de acordo com o diagrama de equilíbrio eletroquímico de Pourbaix [16]. A reação de redução de hidrogênio foi termodinamicamente espontânea para as soluções 5, 5*, 6, 7 e 8 , isso devido ao fato do potencial de corrosão ter se situado abaixo da linha de equilíbrio $\mathrm{H} / \mathrm{H}^{+}$segundo o diagrama de Pourbaix [16]. A solução $5^{*}$, apresentou o potencial a circuito aberto, mais negativo em relação a linha de equilíbrio $\mathrm{H} / \mathrm{H}^{+}$ do que a solução 5 , isso devido ao processo de desaeramento com gás $\mathrm{N}_{2}$ puro.

Considerando os resultados obtidos na Figura 1(b), referente ao ensaio em condição desaerada, pode afirmar-se que a adição de tiossulfato de sódio acentuou o processo de corrosão. Neste caso, as reações 1 e 2 ocorreram entre o metal e a soluções com o tiossulfato de sódio, que tornaram as soluções mais agressivas e anódicas. Isso ocorre porque as bactérias redutoras de sulfato em meio anaeróbico (simuladas pelo tiossulfato de sódio e desaeramento com gás $\mathrm{N}_{2}$ ) ganham a sua energia bioquímica necessária para o crescimento pela redução de sulfato $\left(\mathrm{SO}_{4}{ }^{2-}\right)$ em sulfeto $\left(\mathrm{H}_{2} \mathrm{~S}, \mathrm{HS}^{-}\right)$usando compostos orgânicos naturais como doadores de elétrons, que são oxidados a $\mathrm{CO}_{2}$ (esse processo também é conhecido como respiração de sulfato) [20]. No entanto, se ocorrer a falta de carbono orgânico, devido ao impedimento da transferência de massa pelo biofilme que cobre a superfície do aço, a BRS pode usar o $\mathrm{Fe}^{0}$ como doador de elétrons [21], através da seguinte reação anódica:

$$
F e^{0} \rightarrow \mathrm{Fe}^{2+}+2 e^{-}
$$

Na ausência de oxigênio, os elétrons são aceitos como oxidantes [13]. Assim, as BRS usam $\mathrm{SO}_{4}$ como um agente oxidante. $\mathrm{O}$ sulfato é reduzido a $\mathrm{H}_{2} \mathrm{~S}$ e $\mathrm{HS}^{-}$através da reação:

$$
\mathrm{SO}_{4}^{2-}+9 \mathrm{H}^{+}+8 \mathrm{e}^{-} \rightarrow \mathrm{HS}^{-}+4 \mathrm{H}_{2} \mathrm{O}
$$

Para utilizar $\mathrm{Fe}^{0}$ na reação anódica, as BRS devem formar um biofilme na superfície do metal para ser possível a transferência de elétrons [21]. Assim, as BRS comportam-se como um biocatalisador fornecendo elétrons para a reação de redução do $\mathrm{SO}_{4}{ }^{2-}[13]$

$\mathrm{O}$ tiossulfato de sódio presente na solução permite a geração e estabilização do $\mathrm{H}_{2} \mathrm{~S}$ na superfície do metal [13]. De acordo com o Diagrama de Pourbaix (Figura 2) para o $\mathrm{H}_{2} \mathrm{~S}$, dependendo do potencial aplicado e do $\mathrm{pH}$ da solução, o tiossulfato de sódio reduz a $\mathrm{H}_{2} \mathrm{~S}$ ou a HS- Essas condições são indicadas pelo diagrama E vs. $\mathrm{pH}$ para $\mathrm{H}_{2} \mathrm{~S}$ em equilíbrio termodinâmico, mostrado na Figura 2 [22].

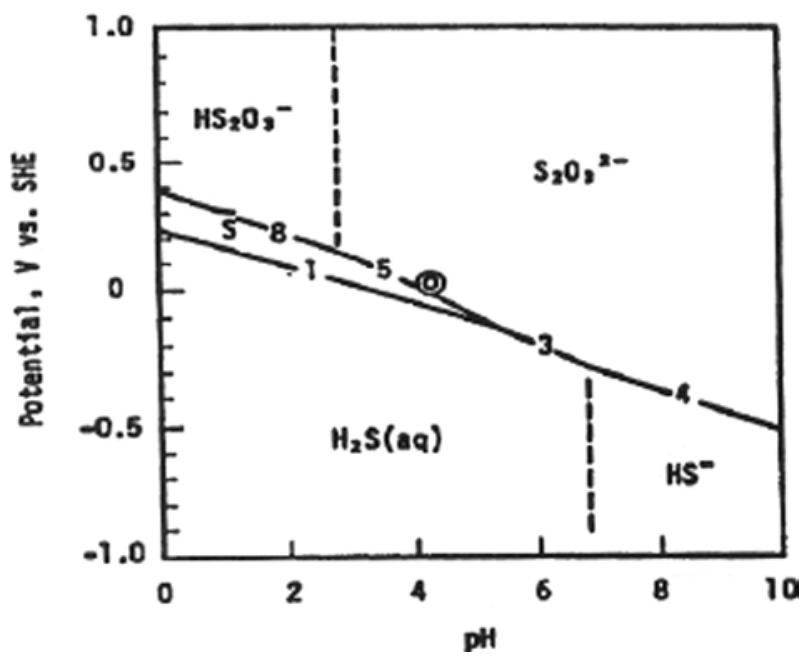

Figura 2: Diagrama de equilíbrio termodinâmico E vs pH para $\mathrm{H}_{2} \mathrm{~S}$ em soluções aquosas [22].

Pela análise Tabela 3, os potenciais de corrosão das soluções 9 a 14 se encontraram dentro do domínio de passivação com estabilidade do óxido de ferro $\left(\mathrm{Fe}_{2} \mathrm{O}_{3}\right)$ para estas soluções, de acordo com o diagrama de equilíbrio eletroquímico de Pourbaix para o sistema $\mathrm{Fe} / \mathrm{H}_{2} \mathrm{O}$ a $25{ }^{\circ} \mathrm{C}$ [16]. Este processo de passivação ocorreu devido a adição do cimento que elevou o pH para em torno de 13. Neste caso, forma-se uma película protetora de óxido em volta do aço que o protege contra o processo de corrosão.

O potencial de corrosão encontrar-se acima da linha de equilíbrio $\mathrm{H} / \mathrm{H}^{+}$, assim não ocorre a reação de redução de hidrogênio. Devido a esse fato, provavelmente, os únicos processos espontâneos que ocorrem na 
superfície do aço, são a redução de oxigênio e a dissolução anódica que provoca a formação do filme de $\mathrm{Fe}_{2} \mathrm{O}_{3}$, por estar dentro do domínio de passivação.

Ainda de acordo com a Tabela 3, ocorreu uma queda de $154 \mathrm{mV}$ no potencial de corrosão da solução 12* (desareada) em relação a solução 12 (naturalmente aerada). Isto ocorreu devido o gás $\mathrm{N}_{2}$ ter expulsado mecanicamente o oxigênio da solução, causando uma queda no potencial de corrosão, segundo o diagrama de Pourbaix [16].

Segundo Gadala e Alfantasi [14], um decréscimo no potencial de corrosão é observado com o um aumento do pH. O que não está de acordo com os resultados obtidos neste trabalho. As soluções 9 a 14, que apresentaram $\mathrm{pH}$ alcalino (pH próximos de 13) exibiram um aumento do potencial de corrosão em relação as soluções com pH próximos a neutro. Essa divergência está relacionada aos valores de $\mathrm{pH}$ utilizados pelos autores bem como a condição de aeração da solução. Os autores relatam que a adição de bicabornato aumenta o pH da solução, contribuindo assim para o aumento da camada passiva e consequentemente para a redução no valor do potencial de corrosão. Porém os valores de $\mathrm{pH}$ utilizados por Gadala e Alfantasi [14] não se situam dentro do domínio de estabilidade do óxido de ferro, ou seja, dentro do domínio de passivação pelo Diagrama Pourbaix [16].

Com base nas curvas de polarização anódica (Figuras 1(c) e 1(d)), todas as sete soluções causaram a passivação do aço. Sendo o domínio de passivação obtido menor para as soluções na presença de tiossulfato (Tabela 4). Esses resultados confirmam o que Gadala e Alfantasi [14] relataram, na qual a corrosividade de uma solução não pode ser determinada qualitativamente apenas pelo seu $\mathrm{pH}$, para comparar a atividade de corrosão com dependência do $\mathrm{pH}$ as condições devem ser as mesmas. Apesar dessas soluções apresentarem pH similares, a presença do tiossulfato de sódio causou uma maior agressividade.

Pode considerar-se que a adição de $10 \%$ e $15 \%$ (m/v) de cimento, não é necessário, uma vez que os domínios de passivação não contribuem para um acréscimo significativo que justifique empregar concentrações maiores que $5 \%(\mathrm{~m} / \mathrm{V})$ de cimento. Assim sendo, é possível inferir que $5 \%(\mathrm{~m} / \mathrm{v})$ de cimento é suficiente para simular uma solução anticorrosiva do solo sintético, uma solução sintética de solo anticorrosivo com a presença de $\mathrm{H}_{2} \mathrm{~S}$ e uma solução sintética de solo anticorrosivo com a presença de BRS.

Tabela 4: Domínio de passivação das soluções onde ocorreu processo de passivação.

\begin{tabular}{|c|c|c|c|c|}
\hline SOLUÇÃo & PH & $\begin{array}{l}\text { POTENCIAL DE CORROSÃO } \\
(\mathrm{mV})(\mathrm{ECS})\end{array}$ & $\begin{array}{c}\text { POTENCIAL DE PITE } \\
(\mathrm{mV})(\mathrm{ECS})\end{array}$ & $\begin{array}{c}\text { DOMÍNIO DE PASSIVAÇÃO } \\
\text { E }_{\mathrm{PIT}}-\mathrm{E}_{\mathrm{CORR}}\end{array}$ \\
\hline 9 & 13,05 & $-281,00$ & 598,14 & 1588,33 \\
\hline 10 & 13,08 & $-290,00$ & 605,01 & 1604,28 \\
\hline 11 & 13,12 & $-296,00$ & 605,16 & 1622,49 \\
\hline 12 & 12,92 & $-194,00$ & 592,89 & 1508,46 \\
\hline $12 *$ & 12,92 & $-357,00$ & 568,39 & 1609,69 \\
\hline 13 & 13,16 & $-277,00$ & 544,28 & 1502,81 \\
\hline 14 & 13,2 & $-281,00$ & 551,13 & 1531,70 \\
\hline 16 & 12,3 & $-457,00$ & $-378,00$ & 637,66 \\
\hline 17 & 12,4 & $-461,00$ & $-291,00$ & 720,94 \\
\hline 18 & 12,5 & $-478,00$ & $-266,00$ & 743,40 \\
\hline
\end{tabular}

As curvas de polarização realizadas para a solução 15 (Figura 1(e)) apresentaram dissolução ativa por se localizar dentro do domínio de corrosão com solubilidade dos íons $\mathrm{Fe}^{2+}$ na concentração de $10^{-6}$ íon $\mathrm{g} \mathrm{L}^{-1}$, segundo o diagrama de Pourbaix [16].

Nesse caso, é possível observar que ao adicionar o cloreto de sódio na solução NS4 padrão (solução1) ocorreu um grande aumento na densidade de corrente anódica (Tabela 2), ou seja, a solução 15 demonstra ser bem mais agressiva que a solução NS4 devido a adição dos íons cloreto. Wang et al [23], chegou em resultados semelhantes em seu trabalho, na qual a densidade de corrente anódica aumenta significativamente com o aumento da concentração de íons cloreto, concluindo que o aumento da taxa de corrosão é proporcional ao aumento do teor de cloreto na solução.

Analisando a Figura 1(f) e a Tabela 4, embora as três soluções tenham apresentado um processo de passivação, elas tiveram menor domínio de passivação em relação as soluções 9 a 14 . Atestando assim que apenas o pH da solução não é indicado para determinar qualitativamente o processo de corrosão [14]. Neste 
caso, pode-se observar que os íons cloretos foram mais agressivos ao aço API X65 que a própria solução NS4 e o tiossulfato de sódio. Assim sendo, pode-se inferir que o filme passivo formado foi instável, sugerindo o rompimento e o processo de corrosão em baixos potenciais, ou seja, os potenciais de pite das três soluções ocorreram em baixos valores, dando origem a pequenos domínios de passivação. Assim, a adição de cimento em $5 \%, 10 \%$ e $15 \%(\mathrm{~m} / \mathrm{v})$ não foi suficiente para causar o processo de passivação com o mesmo domínio de passivação observado nas soluções 9 a 14. Esses resultados estão de acordo com a literatura apresentada por Córdoba et al [6], os autores descrevem que a adição de cimento na proporção de 5 e $10 \%$ (m/v) pode alcançar uma elevada alcalinidade do solo, o que permite a obtenção de valores de pH próximos de 10. No entanto, esta condição não é o suficiente para proporcionar propriedades protetoras para o solo em ambientes contaminados com ions cloreto.

Gadala e Alfantasi [14], relata que os íons cloretos evitam o processo de passivação e pré-passivação, e que mesmo em concentrações que não impendem esse processo, os íons cloretos aceleram as reações anódicas corroendo a superfície do aço.

Foi observado uma redução do potencial de corrosão nas soluções 16, 17 e 18, ao se comparar com as demais soluções que tiveram acréscimo de cimento (soluções 9 a 14). De acordo com Gadala e Alfantasi [14], este comportamento pode ser atribuído a adição de íons cloretos. A adição de íons cloretos e sulfatos reduz o valor do potencial de corrosão, devido a dissolução ativa do metal exposto na solução, ou seja, ao aumento da taxa de corrosão.

Os resultados dos ensaios por espectroscopia de impedância eletroquímica para as soluções estudadas estão representados nas Figuras 3 a 8.
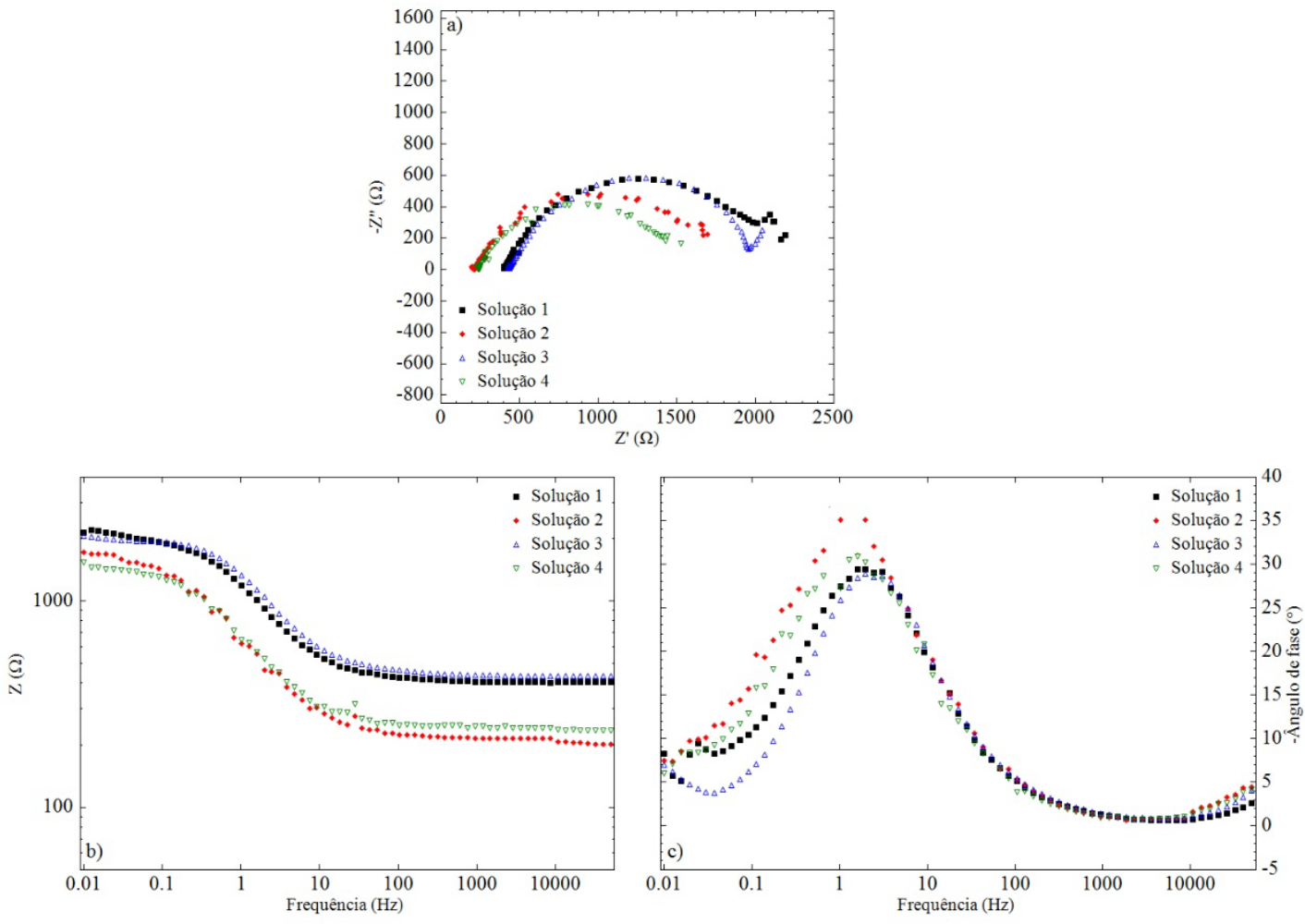

Figura 3: Impedância eletroquímica para soluções sintéticas de solos. (a) Diagramas de Nyquist, (b) Módulo de Bode e (c) Ângulo de fase de Bode.

A impedância, para uma amostra aço, em altas frequências é dominada pela resistência da solução, enquanto que a impedância em baixas frequências é dominada pela resistência de transferência de carga na interface aço/solução [24].

No diagrama de Nyquist (Figura 3(a)) foi possível constatar, em altas frequências, que as soluções 2 e 4 apresentaram uma transferência de elétrons mais intensa em comparação com a solução NS4 padrão (solução 1), pois apresentaram uma menor resistividade do eletrólito (Figura 3(a)), mostrando serem mais agressivas. 
É possível perceber que as soluções 2 e 4 apresentaram um semicírculo na região de baixa frequência, indicando que o processo de corrosão do aço é controlado pelo processo de transferência de carga [25]. Enquanto, nas soluções 1 e 3 os semicírculos progridem para um a linha reta, indicando que o processo de transporte de carga é transferido para o processo de difusão [25], possivelmente esse efeito é decorrente da reação de redução do oxigênio que ocorre nos poros do filme que se forma na superfície do aço proveniente dos produtos de corrosão.

As soluções 2 e 4, em uma mesma frequência obtiveram menores valores de modulo de impedância (Tabela 5) em relação a solução NS4 padrão. A diminuição da impedância é mostrada no gráfico através da redução do arco capacitivo, indicando uma maior agressividade. Isso confirma os resultados obtidos nas curvas de polarização (Figura 1(a)), que por conterem maior porcentagem de íons cloretos, são mais agressivas. Maocheng et al.[24], obteve resultados semelhantes, mostrando que no maior arco capacitivo o processo eletroquímico é suprimido, ou seja, apresenta uma menor taxa de corrosão.

No diagrama de módulo de Bode 3(b) nota-se uma diminuição nos valores de impedância nas baixas frequências nas soluções 2 e 4, o que poderia sugerir a diminuição da resistência à corrosão do aço. He et al.[25], retrata que o módulo de impedância de aço gasoduto X70, em baixas frequências, é inversamente proporcional à taxa de corrosão do aço. Assim as soluções com menor módulo de impedância (soluções 2 e 4) apresentam uma maior taxa de corrosão, o qual está de acordo com os ensaios de polarização (Figura 1(a)).

Na Figura 3(c), o ângulo de fase para as quatro soluções são semelhantes, segundo Wu, et al. [26], esse comportamento indica que processos semelhantes estão ocorrendo na interface metal/solução.

A Tabela 5 mostra os valores do módulo da impedância registrados numa frequência especifica (frequência 0,03009 Hz) para as soluções ensaiadas. Na qual o módulo da impedância é definido por [27]:

$$
Z=\sqrt{\left(Z^{\prime}\right)^{2}+\left(Z^{\prime \prime}\right)^{2}}
$$

Na qual Z’ e Z” são as componentes reais e imaginárias da impedância, respectivamente.

Tabela 5: Dados das curvas de impedância eletroquímica para uma frequência específica.

\begin{tabular}{ccccc}
\hline SOLUÇõES & FREQUÊNCIA (Hz) & $Z^{\prime}$ & $Z^{\prime \prime}$ & MÓDULO DA IMPEDÂNCIA (ohm) \\
\hline 1 & 1,0226 & 1056,90 & 548,71 & 1190,08 \\
2 & 1,0226 & 510,36 & 358,74 & 623,82 \\
3 & 1,0226 & 1197,10 & 581,19 & 1330,72 \\
4 & 1,0226 & 576,59 & 296,62 & 648,41 \\
5 & 1,0226 & 487,26 & 467,36 & 675,16 \\
6 & 1,0226 & 385,60 & 360,59 & 536,31 \\
7 & 1,0226 & 429,33 & 417,02 & 598,52 \\
8 & 1,0226 & 202,53 & 225,48 & 303,08 \\
9 & 1,0226 & 744,51 & 7747,40 & 7773,09 \\
10 & 1,0226 & 692,75 & 6939,10 & 6973,49 \\
11 & 1,0226 & 1037,50 & 8022,80 & 8089,60 \\
12 & 1,0226 & 752,86 & 7528,10 & 7565,65 \\
13 & 1,0226 & 913,34 & 8451,50 & 8500,71 \\
14 & 1,0226 & 819,45 & 7456,10 & 7500,99 \\
15 & 1,0226 & 374,52 & 318,78 & 491,81 \\
16 & 1,0226 & 671,64 & 1680,60 & 1809,84 \\
17 & 1,0226 & 663,53 & 2725,70 & 3457,04 \\
18 & 1,0226 & 634,32 & 2899,50 & 2968,07 \\
\hline
\end{tabular}



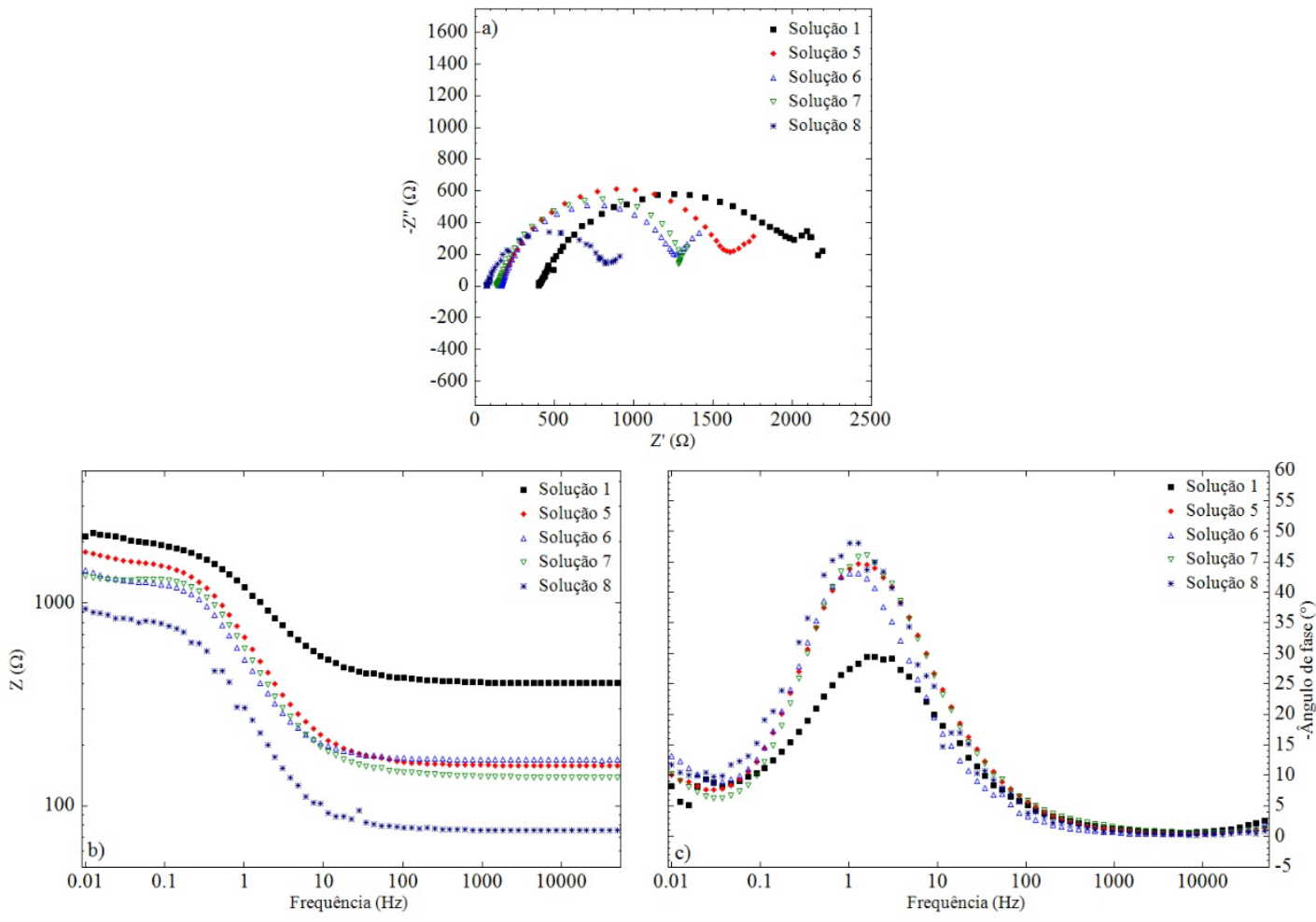

Figura 4: Impedância eletroquímica para soluções sintéticas de solos, na presença de tiossulfato. (a) Diagramas de Nyquist, (b) Módulo de Bode e (c) Ângulo de fase de Bode.

Na Figura 4(a), é possível observar que em altas frequências, o tiossulfato de sódio levou uma menor resistividade das soluções, em comparação com a solução NS4 padrão (solução 1), isso devido a transferência de elétrons ter sido intensificada na superfície do eletrodo [25], indicando a maior agressividade das soluções 5 a 8 .

As soluções 5 a 8 apresentaram o mesmo comportamento das soluções 1 e 3, em baixa frequência, na qual estas evoluem para um a linha reta, apontando que o processo de transporte de carga é transferido para o processo de difusão [25], esse efeito é decorrente da difusão do oxigênio através do filme de produtos de corrosão na superfície do aço $[23,16]$. Nesse caso o filme que se formou é proveniente do tiossulfato de sódio, conhecido como filme negro de sulfeto de ferro [28].

Essas soluções mostraram ser mais agressivas por apresentarem uma diminuição no modulo de impedância em relação a solução NS4 padrão (solução 1), indicado na Tabela 5, ou seja, uma redução do arco capacitivo (Figura 4(a)). Gadala e Alfantazi [14], relatou em seu trabalho que uma redução na resistência de transferência de carga, indica um aumento da taxa de corrosão do aço, essa queda na resistência é apontada pela redução do arco capacitivo. Assim podemos concluir que as soluções com a presença de tiossulfato de sódio (Soluções 5 a 8) apresentam maior taxa de corrosão. Estes resultados estão de acordo com os dados das curvas de polarização (Figura 1(b)), onde as soluções com uma maior concentração de cloreto e de tiossulfato de sódio (solução 8) apresentaram maiores densidade de corrente anódica a $50 \mathrm{mV}$ e $100 \mathrm{mV}$ acima do potencial de corrosão.

A diminuição da impedância nas baixas frequências para as soluções 5, 6, 7, e 8, no diagrama de módulo de Bode, Figura 4(b), indica a diminuição da resistência à corrosão do aço [25]. Sendo a solução 8 a que mais intensificou a diminuição da resistência, estes resultados estão de acordo com aqueles obtidos nas curvas de polarização. Na Figura 4(c), o ângulo de fase da solução 1 é mais elevado do que as demais soluções, assinalando que possivelmente é mais resistiva que as soluções com a presença de tiossulfato de sódio. 

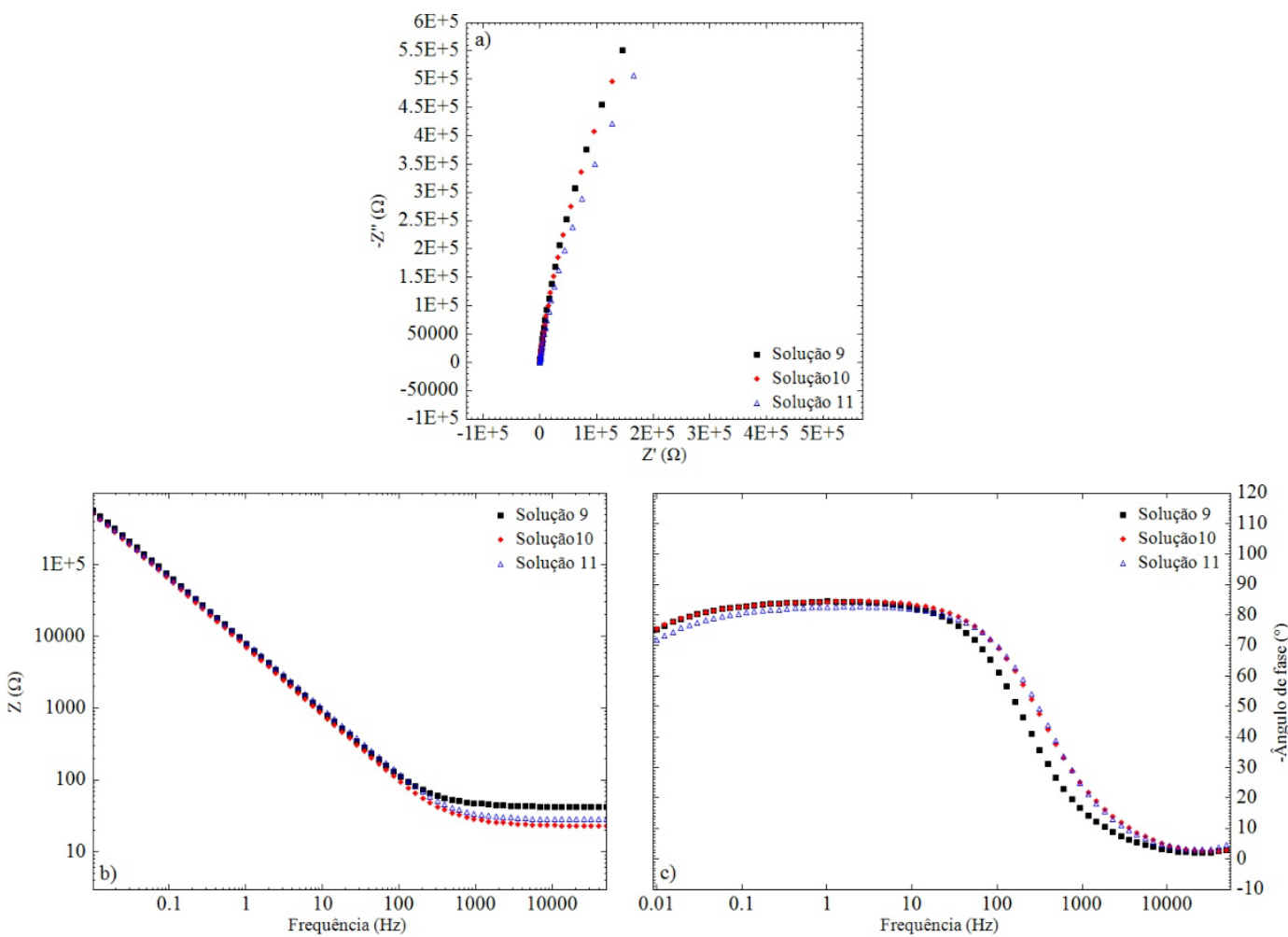

Figura 5: Impedância eletroquímica para soluções sintéticas de solos, na presença de cimento. (a) Diagramas de Nyquist, (b) Módulo de Bode e (c) Ângulo de fase de Bode.
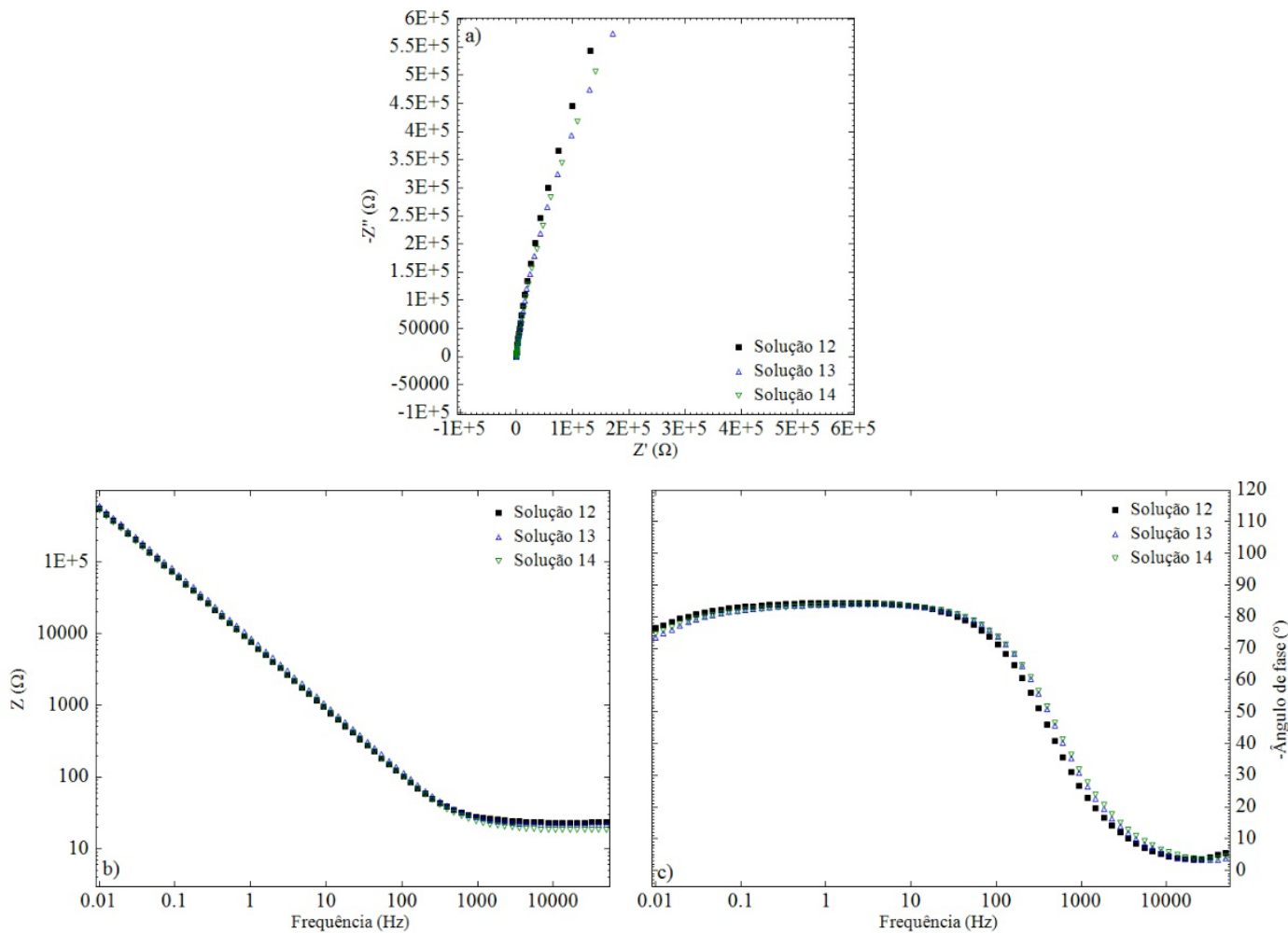

Figura 6: Impedância eletroquímica para soluções sintéticas de solos, na presença de tiossulfato e cimento. (a) Diagramas de Nyquist, (b) Módulo de Bode e (c) Ângulo de fase de Bode. 
O mecanismo de corrosão para as soluções 9 a 14 sinalizaram uma mudança em relação a solução 1, que pode ser percebido pelos diagramas de Nyquist, Figuras 3(a), 5(a) e 6(a). Como citado anteriormente o processo de corrosão do aço imerso na solução NS4 padrão (solução 1) é controlado pelo processo de transferência de carga, por apresentar um semicírculo na região de baixa frequência. Enquanto, as soluções com a presença de cimento, em baixas frequências, exibiram a forma de linha reta como comportamento, indicando uma sobreposição dos semicírculos, relativos ao processo de transferência de carga e ao processo de difusão, que ocorre através da camada passiva [29], isso devido as soluções apresentarem condições termodinamicamente estáveis para a criação do filme de óxido [16].

Pela Tabela 5, percebe-se um aumento dos valores do módulo de impedância em relação a solução NS4 padrão (solução 1), indicando um maior grau de resistividade, ou seja, uma menor taxa de corrosão [14,24]. É importante considerar que comparando as soluções 9, 10 e 11 com a soluções 12 , 13 e 14, todo os testes com tiossulfato de sódio apresentaram um módulo da impedância menor, indicando uma menor resistência a polarização, assim reforçando sua maior agressividade.

Pelo diagrama de módulo de Bode (Figura 5(b) e 6(b)), percebe-se que as curvas das soluções 9, 10 e 11 foram semelhantes, o mesmo é observado para as soluções 12 , 13 e 14, indicando que a resistência a corrosão do aço imerso não se alterou mudando a concentração de cimento [25].

O diagrama de ângulo de fase de Bode (Figura 5(c) e 6(c)) mostra uma larga faixa horizontal em baixas e médias frequências, com os ângulos quase invariáveis entre $-70^{\circ} \mathrm{e}-85^{\circ}$, bem como um patamar entre $0,01 \mathrm{~Hz}$ e $100 \mathrm{~Hz}$. Segundo Xin e Li [29], esse comportamento aponta a sobreposição dos processos difusivos e de transferência de carga.

As Figura 5(c) e 6(c), mostram que os mecanismos para o aço nas soluções são equivalentes, pois apresentaram caráter resistivo e capacitivo semelhantes, para toda faixa de frequência. Esses resultados mostram que as soluções 9, 10 e 11 apresentam um caráter capacitivo maior que as soluções 1 a 4 (Figura 3(c)), pois os maiores ângulos se encontram nas faixas de baixas e médias frequências, enquanto que das soluções 1 a 4 encontram-se nas médias frequências. O mesmo comportamento ocorre para as soluções 12, 13 e 14 (Figura 6(c)) em relação as soluções 5 a 8 (Figura 4(c)).
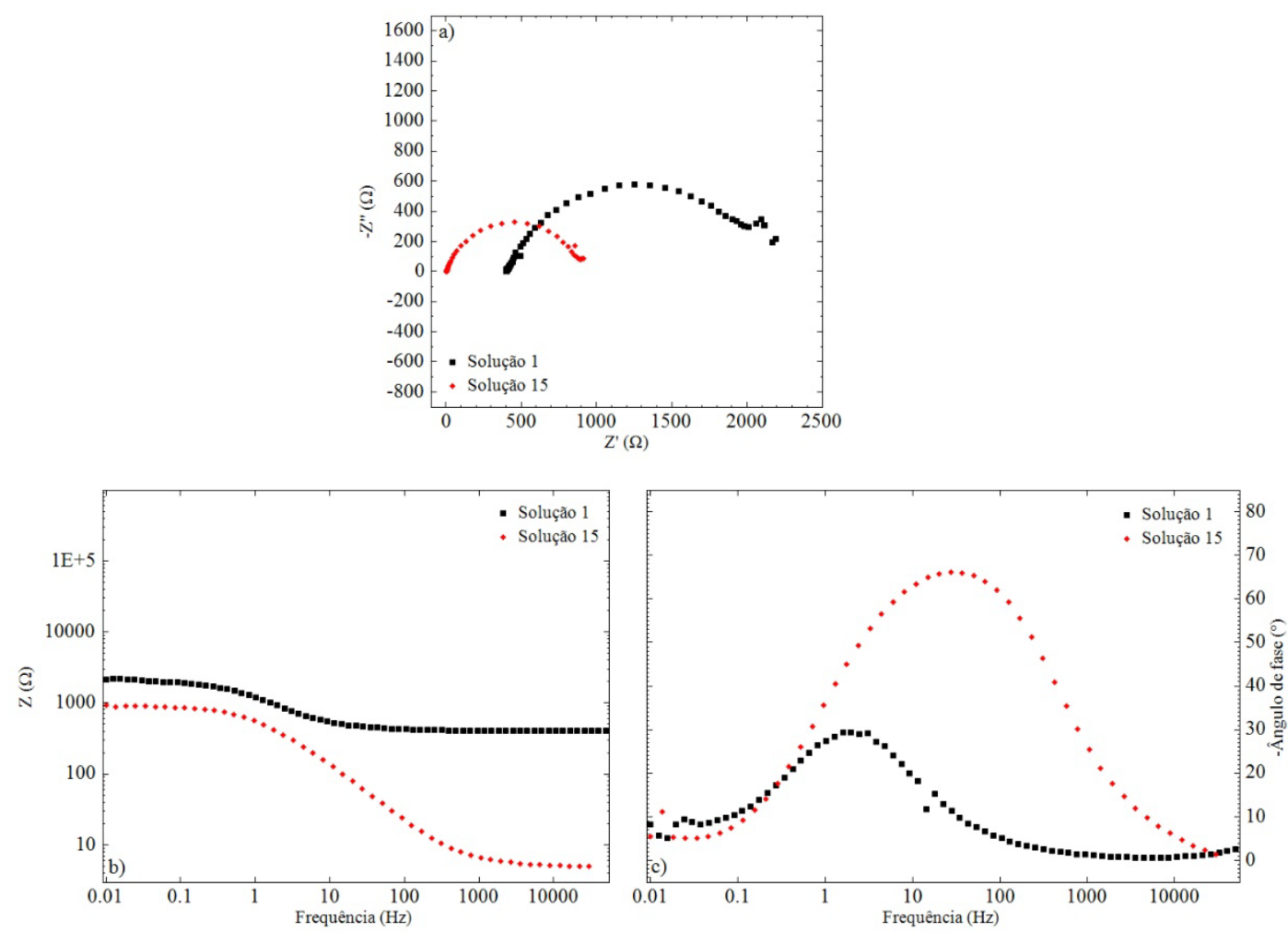

Figura 7: Impedância eletroquímica para soluções sintéticas de solos, na presença de cloreto (a) Diagramas de Nyquist, (b) Módulo de Bode e (c) Ângulo de fase de Bode. 
A Figura 7(a) representa Diagrama de Nyquist para a solução 15, no qual a curva esboçou arco capacitivo distinto, quando comparado com a solução 1, sendo que a solução 15 apresenta o menor arco capacitivo, onde pode ser comprovado pelo menor valor de módulo de impedância (Tabela 5) e menor resistência à polarização [14,24], mostrando que processo eletroquímico é mais intenso. Esses resultados confirmam os dados das curvas de polarização, na qual a solução 15 apresenta maior densidade de corrente.

Em altas frequências os íons cloreto diminuem a resistividade da solução, devido a transferência de elétrons ter sido intensificada na superfície do eletrodo [25].

No diagrama de módulo de Bode 7(b) nota-se uma diminuição da impedância na solução 15, sugerindo uma diminuição da resistência à corrosão do aço [25]. Estes resultados estão de acordo com aqueles obtidos nas curvas de polarização.

A Figura 7(c) mostra valores muitos distintos do maior ângulo de fase. Na solução 1 o maior ângulo de fase $\left(-30^{\circ}\right)$ é mais elevado que o da solução $15\left(-67^{\circ}\right)$, indicando que possivelmente a solução 1 é mais resistiva do que a solução 15 .
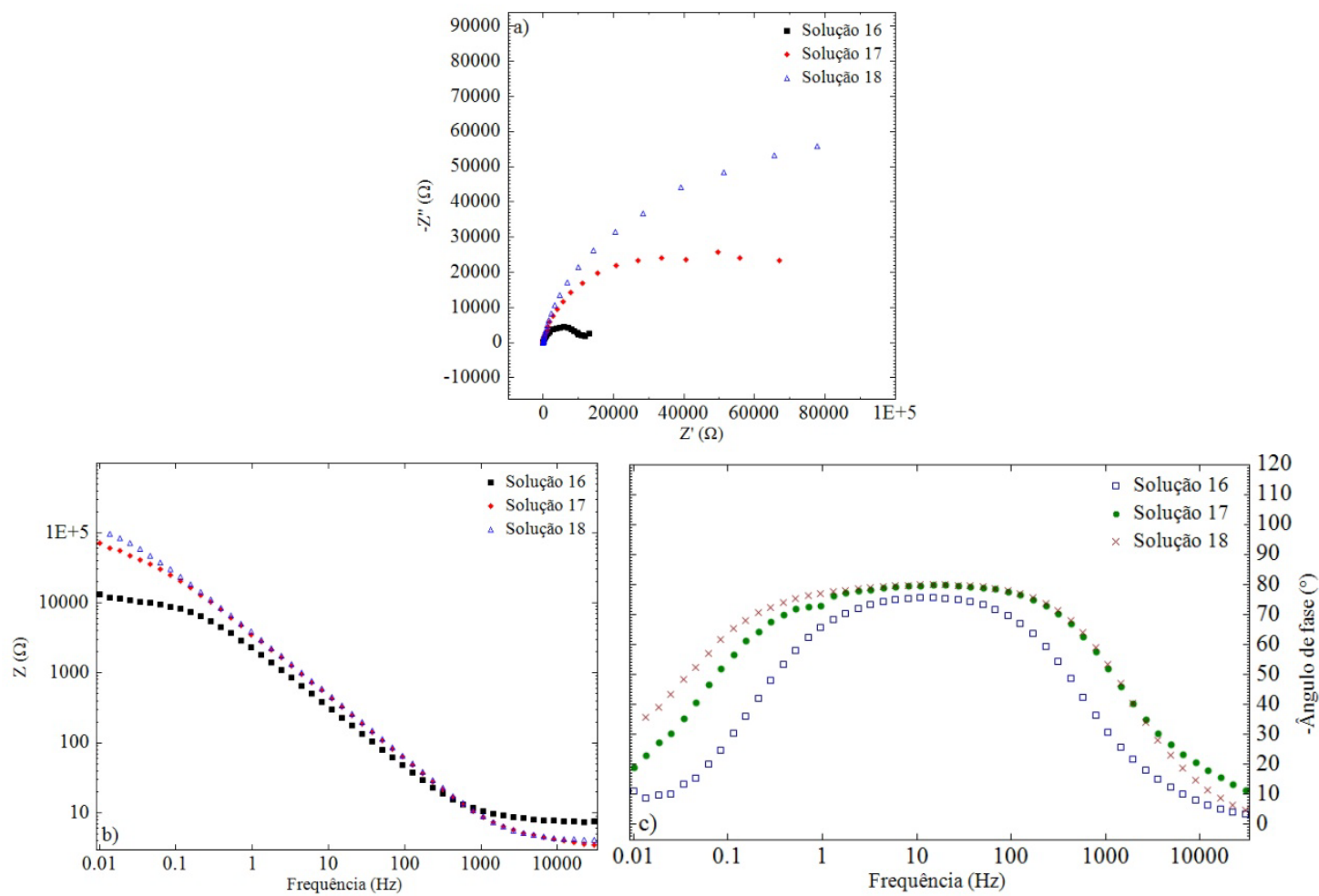

Figura 8: Impedância eletroquímica para soluções sintéticas de solos, na presença de cloreto e cimento (a) Diagramas de Nyquist, (b) Módulo de Bode e (c) Ângulo de fase de Bode.

A Figura 8(a) mostra o diagrama de Nyquist para as soluções 16, 17 e 18, na qual pode se perceber que nas regiões de altas frequências as amostras apresentaram comportamento similar. A partir das frequências intermediárias até as frequências menores, verifica-se que a solução 18 apresentou maiores valores para Zreal e Zimag, esse comportamento sugere um aumento na resistência à corrosão do aço, acarretando em um arco mais capacitivo nessa solução. A amostra imersa na solução 16 apresentou desempenho capacitivo inferior (Tabela 5).

Pelo ensaio de polarização concluímos que o cimento não foi suficiente para criar um filme passivo estável na superfície do metal nas soluções com 3,5\% (m/v) NaCl, mas ao comparar a solução 15 com as soluções 16, 17 e 18 (Tabela 5), percebe-se que o cimento causou um grande aumento na impedância, assim as curvas apresentam maior resistência, principalmente as soluções 17 e 18 .

O arco capacitivo das soluções 16, 17 e 18 diminuíram em relação as soluções 9, 10 e 11, isso devido, a adição de íons cloretos, que como já explicado anteriormente, deixaram a solução mais agressiva. He et al [25], descreve em seus ensaios os íons agressivos presentes na solução penetram na superfície do metal através dos poros e de defeitos na película gerando a corrosão. Nesse caso, podemos concluir que os íons cloretos 
penetraram no filme de óxido aumentando a taxa de corrosão.

Em baixas frequências a solução 16 apresentou um menor modulo de impedância, pelo diagrama do módulo de Bode (Figuras 8(b)), o que sugere uma diminuição da resistência à corrosão do aço imerso nessa solução [25]. Pelo ângulo de fase (Figura 8(c)) constata-se um aumento no caráter capacitivo nas soluções 18 e 17, pois o maior ângulo $\left(-80^{\circ}\right)$ se encontram nas faixas de baixas e médias frequências, enquanto que na solução 16 o maior ângulo $\left(-60^{\circ}\right)$, encontram-se nas médias frequências. O ângulo de fase das soluções 18 e 17 são mais elevados, indicando que possivelmente é mais resistivo do que a solução 16.

Os circuitos eletroquímicos, são utilizados para ajustar os dados da espectroscopia de impedância eletroquímica [24]. O arco de baixa frequência (abaixo de $100 \mathrm{~Hz}$ ) no diagrama de Nyquist está associada com o processo de corrosão na interface aço/solo [24]. O circuito da Figura 9(a) representa o processo de corrosão na interface eletrólito/aço carbono API X65 que apresenta dissolução ativa, na qual Re representa a resistencia do eletrolito e o par em paralelo CPE1R1 o arco de baixa frequencia. O elemento de fase constante CPE1, representa a capacitância do aço API X65 e R1 a resistência a transferência de cargas entre o aço carbono e a solução.

Para as soluções que a impedância asumiu valores mais elevados, ou seja, aquelas que ocorreu o processo de passivação, o processo de corrosão ocorreu na interface eletrólito/pelicula de óxido. O circutio equivalente que represente esse processo está esbocado na Figura 9(b). O circuito é composto pelo Re, resistencia do eletrolito, elemento de fase constante CPE1, que representa a capacitância do aço API X65, R1 resistência a transferência de cargas entre a película de oxido formada na superficie do aço carbono e a solução, os elementos R2 e CPE2 representam a resistência de polarização da transferência de carga e a capacitância na interface da camada passiva e metal, o que significa que é a camada interna do filme de óxido.

a)

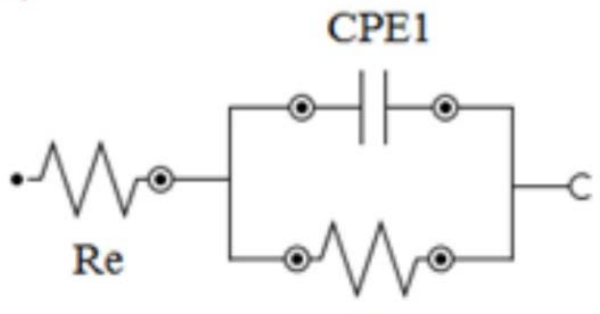

R1 b) $\quad$ CPE1

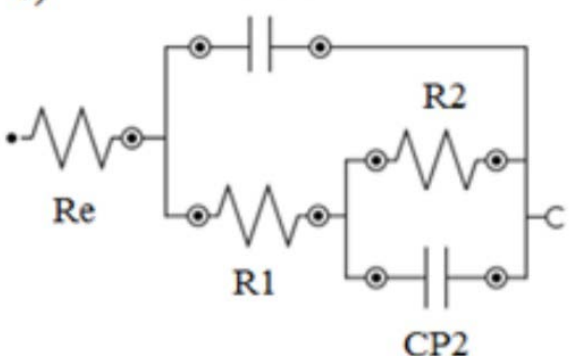

Figura 9: Circuito elétrico proposto para o aço API X65 exposto a) soluções 1, 2, 3, 5, 5*, 6, 7, 8, 15, 16, b) soluções 9, $10,11,12,12 *, 13,14,17$ e 18.

A Figura 10 apresenta as curvas de perda de massa para as soluções no aço carbono API X65.
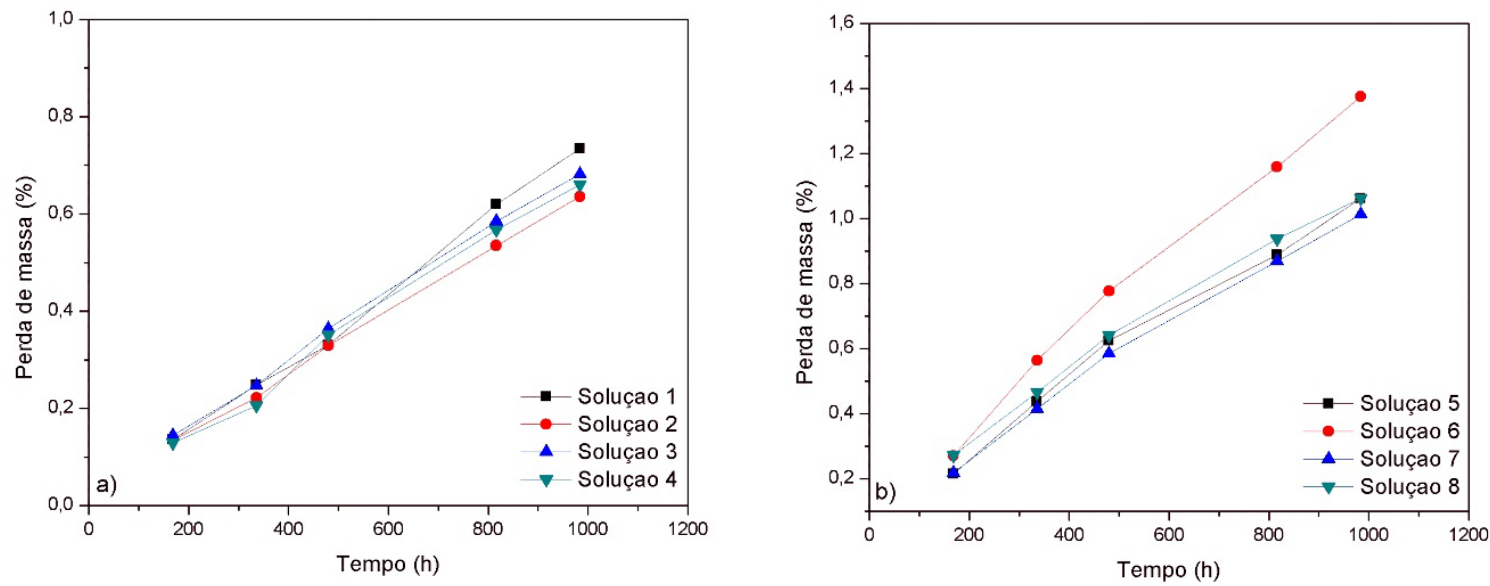

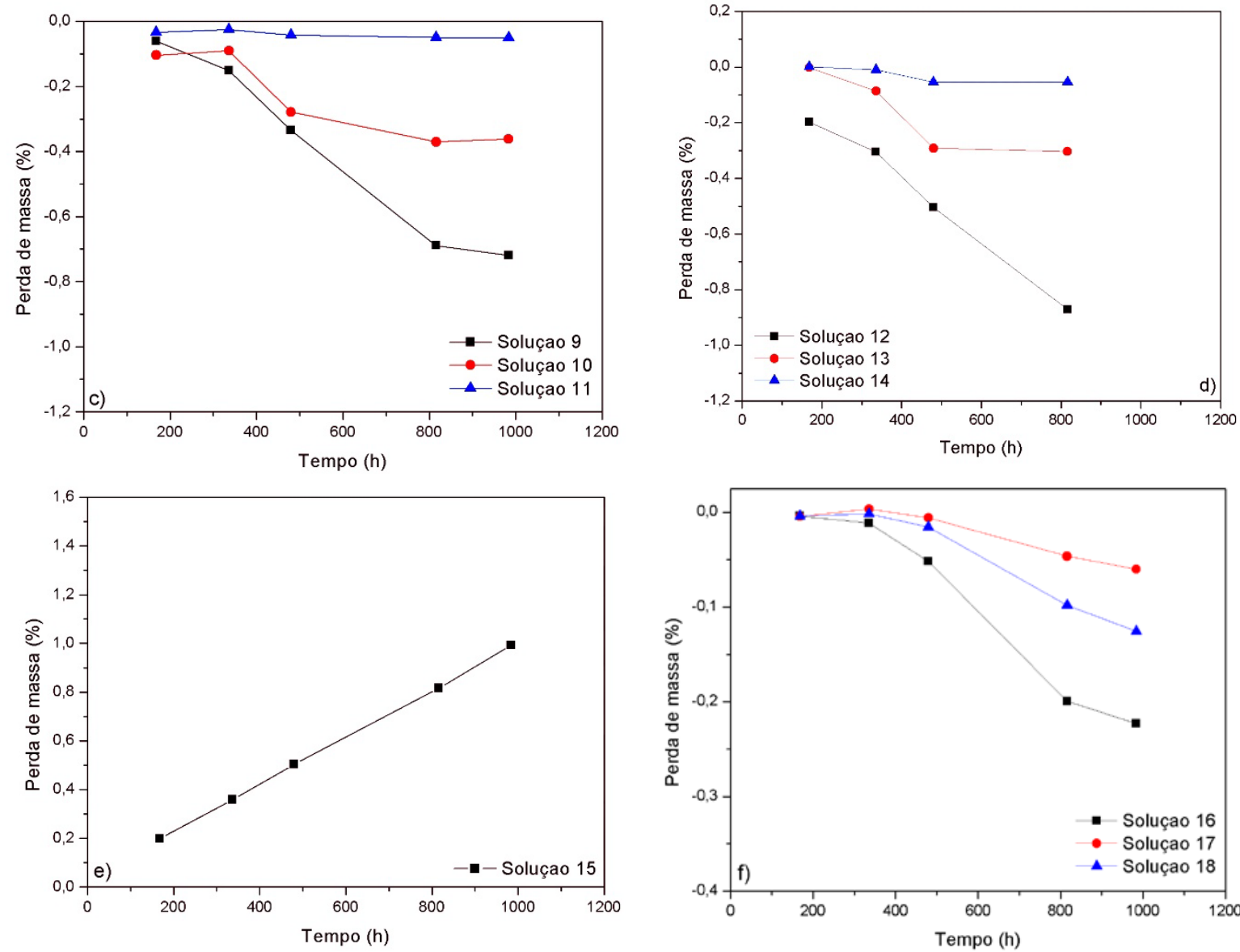

Figura 10: Perda de massa em condições, naturalmente aeradas, obtidas com o aço API X65 nas soluções de teste.

A perda de massa ocasionada pelas quatro primeiras soluções foi praticamente a mesma como pode ser visto na Figura 10(a) (em torno de 0,7\%). Isso provavelmente significa que o acréscimo na composição dos reagentes não alterou de modo significativo a corrosividade das soluções.

As soluções que contém em sua composição o tiossulfato de sódio (soluções 5, 6, 7 e 8) acarretaram uma maior perda de massa que a solução NS4 padrão (Figura 10(b)), na qual essas soluções obtiveram uma perda em torno de 1\%. Comprovando assim que o tiossulfato de sódio tornou as soluções mais agressivas, o que está de acordo com o teste de polarização e impedância. Segundo Kappes et. Al [28], depois de um período de exposição, de cerca de um dia, em solução com suspensão enxofre, causa o aparecimento de um filme negro de sulfeto de ferro, com a evolução do sulfeto de hidrogênio, proveniente do tiossulfato de sódio. A formação desse filme pode progredir a taxas catastróficas. Dentre essas soluções a que levou a uma maior perda de massa foi a solução 6 (1,38\%), que apresentou em sua composição $10 \%$ a mais de íons cloreto.

As soluções 9 a 14 (Figura 10(c) e 10 (d)) provocaram um aumento no percentou de massa, isso devido ao processo de passivação, na qual se formou um filme de óxido de ferro sobre a superficie do corpo de prova. Esse processo ocorreu devido a adição de cimento que levou as soluções a condições de alcalinidade, se situando dentro do domínio de passivação, de acordo com o diagrama de equilíbrio eletroquímico de Pourbaix para o sistema $\mathrm{Fe} / \mathrm{H}_{2} \mathrm{O}$ a $25^{\circ} \mathrm{C}$ [16].

A solução com adição de $5 \%(\mathrm{~m} / \mathrm{v})$ de cimento (solução 9 e 12) apresentaram um maior ganho de massa, sendo esse ganho de $0,72 \%$ e $1,09 \%$, e a solução com $15 \%(\mathrm{~m} / \mathrm{v}$ ) de cimento (solução 11e 14) um menor de ganho, de $0,05 \%$ e $0,07 \%$ respectivamente. Segundo Córdoba et al. [6], porcentagens maiores que $5 \%(\mathrm{~m} / \mathrm{v})$ de cimento formam uma rápida camada na superficie do metal, o que o torna menos resistente.

As soluções 12, 13 e 14 (Figura 10(d)) causaram um maior ganho de massa que as soluções 9, 10 e 11 (Figura 10(c)), isso provavelmente aconteceu porque além da formação do filme de óxido de ferro, ocorre também a formação do filme de sulfeto de ferro, filme negro [28] na superfície do metal.

A solução 15 (Figura 10(e)), que possui 3,5\% (m/v) de $\mathrm{NaCl}$ em sua composição também ocasionou 
uma perda de massa em torno de 1\%, que foi superior que a da solução NS4 padrão (Solução 1) que apresentou $0,73 \%$ de perda. Esse comportamento indica, como esperado, que os íons cloretos levam a uma maior agressividade da solução, uma vez que os íons cloretos aceleram as reações anódicas atacando a superfície do aço [14], o que está de acordo com os testes de polarização e impedância.

Como discutido anteriormente, os corpos de prova imersos nas soluções 16, 17, e 18 também apresentaram um ganho de massa, por causa da formação do filme de óxido (Figura 10(f)). Como explanado anteriormente o solução 16 , que contém $5 \%(\mathrm{~m} / \mathrm{v})$ causou um maior ganho de massa $(0,22 \%)$ e a solução 17 que na sua composição contém $10 \%(\mathrm{~m} / \mathrm{v})$ de cimento um menor de ganho $(0,06 \%)$. Essas soluções, com acréscimo de 3,5\% (m/v) levaram a um menor ganho de massa em comparação as soluções 9 a 14, indicando serem mais agressivas. . Esses resultados também foram obtidos nos ensaios de polarização e impedância eletroquímica .

\subsection{Proposição das soluções sintéticas de solos contaminados}

Como descrito anteriormente, Parkins [11] desenvolveu a solução NS4 que é amplamente utilizada para simular solos sintéticos. Considerando a diversidade das propriedades físico-químicas que um solo pode apresentar, a solução NS4 não é ideal para simular todos os tipos de solo. Assim, a partir da solução NS4 é proposto outras soluções sintéticas para uso em laboratório que abranjam uma variedade de tipos de solos com diferentes propriedades físico-químicas.

Com base nos resultados discutidos nos ensaios de polarização potenciodinâmica, espectroscopia de impedância eletroquímica e perda de massa é sugerido 7 soluções sintéticas de solos para uso em laboratório.

A solução 5, naturalmente aerada, é proposta para simular Solução Sintética de Solo contaminado com $\mathrm{H}_{2} \mathrm{~S}$, a solução 5*, desaerada com gás $\mathrm{N}_{2}$ puro, uma Solução Sintética de Solo contaminado com Bactérias Redutoras de Sulfato, a solução 9, naturalmente aerada, para uma Solução Sintética de solo Anticorrosivo, a solução 12, naturalmente aerada, como uma Solução Sintética de Solo Anticorrosivo contaminado com $\mathrm{H}_{2} \mathrm{~S}$, a solução 12*, desaerada com gás $\mathrm{N}_{2}$ puro, para uma Solução Sintética de Solo Anticorrosivo contaminado com Bactérias Redutoras de Sulfato, a solução 15 simula uma Solução sintética de Solo em Região Costeira e a solução 17, e proposta para simular um Solução sintética de Solo anticorrosivo em Região Costeira.

A Tabela 6 apresenta as novas 7 soluções sintéticas propostas e suas composições.

Tabela 6: Novas soluções sintéticas de solos contaminados para uso em laboratório e suas composições.

\begin{tabular}{|c|c|c|c|c|c|c|c|c|}
\hline \multirow{2}{*}{$\begin{array}{l}\text { SOLUÇÃO SIN- } \\
\text { TÉTICA DE SO- } \\
\text { LO CONTAMI- } \\
\text { NADO }\end{array}$} & \multicolumn{4}{|c|}{ CONTEÚDO } & \multirow[b]{2}{*}{$\begin{array}{l}\mathrm{NaS}_{2} \mathrm{O}_{3} \cdot 5 \mathrm{H}_{2} \mathrm{O} \\
(\mathrm{g} / \mathrm{L})\end{array}$} & \multirow[b]{2}{*}{$\begin{array}{l}\mathrm{NaCl} \\
(\%)\end{array}$} & \multirow[b]{2}{*}{$\begin{array}{l}\text { CIMENTO } \\
\%(\mathrm{~m} / \mathrm{v})\end{array}$} & \multirow[b]{2}{*}{$\begin{array}{l}\text { GÁS } \\
\text { N2 }\end{array}$} \\
\hline & $\begin{array}{l}\mathrm{KCl} \\
(\mathrm{g} / \mathrm{L})\end{array}$ & $\begin{array}{l}\mathrm{CaCl}_{2} \\
\text { (g/L) }\end{array}$ & $\begin{array}{l}\mathrm{NaHCO}_{3} \\
(\mathrm{~g} / \mathrm{L})\end{array}$ & $\begin{array}{l}\mathrm{MgSO}_{4} \cdot 7 \mathrm{H}_{2} \mathrm{O} \\
\text { (g/L) }\end{array}$ & & & & \\
\hline $\mathrm{H}_{2} \mathrm{~S}$ & 0,122 & 0,093 & 0,483 & 0,131 & 2,481 & 0 & 0 & Não \\
\hline BRS & 0,122 & 0,093 & 0,483 & 0,131 & 2,481 & 0 & 0 & Sim \\
\hline Anticorrosiva & 0,122 & 0,093 & 0,483 & 0,131 & 0 & 0 & 5 & Não \\
\hline $\begin{array}{c}\text { Anticorrosiva/ } \\
\qquad \mathrm{H}_{2} \mathrm{~S}\end{array}$ & 0,122 & 0,093 & 0,483 & 0,131 & 2,481 & 0 & 5 & Não \\
\hline $\begin{array}{l}\text { Anticorrosi- } \\
\text { va/BRS }\end{array}$ & 0,122 & 0,093 & 0,483 & 0,131 & 2,481 & 0 & 5 & Sim \\
\hline Costeira & 0,122 & 0,093 & 0,483 & 0,131 & 0 & 3,5 & 0 & Não \\
\hline $\begin{array}{l}\text { Anticorrosi- } \\
\text { va/Costeria }\end{array}$ & 0,122 & 0,093 & 0,483 & 0,131 & 0 & 3,5 & 10 & Não \\
\hline
\end{tabular}

\section{CONCLUSÕES}

O aço carbono API X65 apresentou uma dissolução ativa em todas as soluções sintéticas de solo testadas, exceto nas condições na presença de cimento. A maior taxa de dissolução anódica ocorreu nas condições com cloreto mais concentrado e na solução em meio de tiossulfato de sódio.

A adição de cimento provoca um aumento do $\mathrm{pH}$, deixando o ambiente mais alcalino. Este fato pode trazer grandes vantagens no que diz respeito à resistência à corrosão, porque é possível se formar um óxido 
cobrindo o aço, nomeado como o estado de passivação do material.

Comparando-se os testes, foi observado que o tiossulfato de sódio e cloreto de sódio foram os agentes mais agressivos nas soluções sintéticas. Para garantir o processo passivo no metal na presença de tiossulfato foi preciso adicionar $5 \%(\mathrm{~m} / \mathrm{v})$ de cimento na solução sintética. Enquanto que, na presença do cloreto de sódio, na qual a adição cimento nas concentrações estudadas, não foram suficientes para criar um filme passivo estável.

Pelos testes de perda de massa, acréscimos de cimento superiores que $5 \%(\mathrm{~m} / \mathrm{v})$ não têm nenhum efeito adicional em termos de proteção contra a corrosão no aço.

O estudo das soluções sintéticas de solo propostas no presente trabalho, provenientes da solução NS4, possibilitou uma abrangência a solos com diferentes propriedades físico-químicas, podendo ser amplamente empregadas em laboratórios. Com isso podemos concluir que essas soluções podem ser usadas para simular solos contaminados com $\mathrm{H}_{2} \mathrm{~S}$, solo em condições anaeróbicas na presença de bactérias redutoras de sulfato, solos de regiões costeiras, bem como solos anticorrosivos.

\section{AGRADECIMENTOS}

Esta pesquisa foi financiada por CAPES, CNPq, FAPEMIG e UFSJ.

\section{BIBLIOGRAFIA}

[1] RIN-RUKEH,A., AWATEFE,J. K. "Investigation of Soil Corrosivity in the Corrosion of Low Carbon Steel Pipe in Soil Environment”, Journal of Applied Sciences Research, v. 8, n. 2, pp. 466-469, 2006.

[2] FERREIRA, C. A. M., PONCIANO, J. A. C.; VAISTSMAN, D. S., et al., "Evaluation of the corrosivity of the soil through its chemical composition", Science of the Total Environment, v. 388, pp. 250-255, September 2007.

[3] SERRA, E. T. Corrosão e proteção anticorrosiva dos metais no solo, Interciência, v. 1, p.1-182, 2014.

[4] YAN, M., SUN, C., XU, J., et al., "Role of Fe oxides in corrosion of pipeline steel in a red clay soil", Corrosion Science, v. 80, pp. 309-317, March 2014.

[5] HE, D. X., CHEN,W., LUO, J. L. "Effect of Cathodic Potential on Hydrogen Content in a Pipeline Steel Exposed to NS4 Near-Neutral pH Soil Solution", NACE International. Corrosion, v. 60, n. 8, pp. 778-786, 2004.

[6] CÓRDOBA, C., MEJÍA, M. A., CALDERÓN, J. A., et al., "Mitigação da Corrosão de Estruturas Enterradas por Modificação do Solo”, In: INTERCORR, pp. 24-28, Fortaleza, Brasil, Maio 2010.

[7] ISMAIL, A. I. M., EL-SHAMY, A. M. "Engineering behavior of soil materials on the corrosion of mild steel”, Applied Clay Science, v. 42, n. 3-4, pp. 356-362, January 2009.

[8] ROBINSON, W. C. “Testing Soil for Corrosiveness”, Materials Performance, v. 32, n. 4, pp. 56-58, April, 1993.

[9] BRADFORD, S. Practical Handbook of Corrosion Control in Soils. Alberta., CASTIPublications, 2002.

[10] ROCHA, S. M. S. Avaliação da Utilização de Nitrato por Cultura Mista Enriquecida com Bactérias Redutoras de Sulfato (BRS) em Efluente Contendo Sulfato, Dissertação M.Sc., Universidade Federal de Uberlandia, Urbelandia, Minas Gerais, Brasil, 2006.

[11] PARKINS, R. N., BLANCHARD, W. K., DELANTY, B. S. "Transgranular Stress Corrosion Cracking of High-Pressure Pipelines in Contact With Solutions of Near Neutral pH", NACE International. Corrosion, v. 50, n. 5, pp. 394, August 1993.

[12] ROBERGE, P. R. Handbook of Corrosion Engineering, McGraw-Hill. 1999.

[13] BUENO, A.H.S., MOREIRA, E.D., SIQUEIRA, P. et al., "Effect of cathodic potential on hydrogen permeation of API grade steels in modified NS4 solution”, Materials Science \& Engineering: A, v. 597, pp. 117-121, March 2014.

[14] GADALA, I. M., ALFANTAZI, A. "Electrochemical behavior of API-X100 pipeline steel in NS4, nearneutral, and mildly alkaline pH simulated soil solutions”, Corrosion Science v. 82, pp. 45-57, May 2014.

[15] BUENO, A.H.S., MOREIRA, E.D., GOMES, J.A.C.P. "Evaluation of stress Corrosion cracking and hydrogen embrittlement in an API grade steel”, Engineering Failure Analysis, v. 36, pp. 423-431, January 2014.

[16] POURBAIX, M. Atlas of electrochemical equilibria in aqueous solutions. 2 ed. Nace international, 
Cebelcor; 1974.

[17] NIU, L., CHENG, Y. F. “Corrosion behavior of X-70 pipe steel in near-neutral pH solution”, Applied Surface Science, v. 253, n. 21, pp. 8626-8631, August 2007.

[18] HA, M. H., GADALA, I. M., ALFANTAZI, A. "Hydrogen Evolution in a API X100 line pipe steel exposed to near-neutral pH solutions”, Electrochimica Acta, v. 204, pp. 18-30, June 2016.

[19] COLE, I.S., MARNEY, D. "The science of pipe corrosion: A review of the literature on the corresion of ferrous metals in soils”, NACE International Corrosion, v. 56, pp. 5-16, March 2012.

[20] VENZLAFF, H., ENNING, D., SRINIVASAN, J., et al., “Accelerated cathodic reaction in microbial corrosion of iron due to direct electron uptake by sulfate-reducing bacteria”, Corrosion Science, v. 66, pp. 88-96, January 2013.

[21] XU, D., LI, Y., SONG, F., et al., "Laboratory investigation of microbiologically influenced corrosion of C1018 carbon steel by nitrate reducing bacterium Bacillus licheniformis”, Corrosion Science, v. 77, pp. 385390, December 2013.

[22] THAUER, R. K., STACKEBRANDT, E., HAMILTON, W. A. In: Barton, L. L.; Hamilton, W.A. (Eds.), Sulphate-Reducing Bacteria: Environmental and Engineered Systems. Cambridge University Press, Cambridge, UK, 2007.

[23] WANG, Y., CHENG, G., WU, W., et al., "Effect of pH and chloride on the micro-mechanism of pitting corrosion for high strength pipeline steel in aerated $\mathrm{NaCl}$ solutions”, Applied Surface Science, v. 349, pp. 746-756, September 2015.

[24] MAOCHENG, Y. A. N., JIN, X. U., LIBAO Y. U., et al., "EIS analysis on stress corrosion initiation of pipeline steel under disbonded coating in near-neutral pH simulated soil electrolyte”, Corrosion Science, v. 110, pp. 23-34, September 2016.

[25] YAN, M., SUN, C., DONG, J., et al., "Electrochemical investigation on steel corrosion in iron-rich clay”, Corrosion Science, v. 97, pp. 62-73, August 2015.

[26] HE, B., LU, C., HAN, P., et al., "Short-term electrochemical corrosion behavior of pipeline steel in saline sandy environments”, Engineering Failure Analysis, v. 59, pp. 410-418, January 2016.

[27] WU, T., XU, J., SUN, C., et al., "Microbiological corrosion of pipeline steel under yield stress in soil environment”, Corrosion Science, v. 88, pp. 291-305, November 2014.

[28] RESENDE, C. Comportamento de inibidores de corrosão para concretos em ambientes contaminados com dióxido de carbono e cloretos, Dissertação M.Sc., UFSJ, São João del Rei, MG, Brasil, 2014.

[29] KAPPES, M., FRANKEL, G. S., SRIDHAR, N., et al., "Reaction Paths of Thiosulfate during Corrosion of Carbon Steel in Acidified Brines”, Journal of The Electrochemical Society, v. 159, n. 4, pp. 195-204, February 2012.

[30] XIN, S. S., LI, M. C. "Electrochemical corrosion characteristics of type 316L stainless steel in hot concentrated seawater”, Corrosion Science, v. 81, pp. 96-101, April 2014. 